\title{
Optogenetic Inhibition of Dorsal Medial Prefrontal Cortex Attenuates Stress-Induced Reinstatement of Palatable Food Seeking in Female Rats
}

\author{
Donna J. Calu, ${ }^{1}$ Alex B. Kawa, ${ }^{1}$ Nathan J. Marchant, ${ }^{1}$ Brittany M. Navarre, ${ }^{1}$ Mark J. Henderson, ${ }^{1}$ Billy Chen, ${ }^{1}$ \\ Hau-Jie Yau, ${ }^{1}$ Jennifer M. Bossert, ${ }^{1}$ Geoffrey Schoenbaum, ${ }^{1}$ Karl Deisseroth, ${ }^{2}$ Brandon K. Harvey, ${ }^{1}$ Bruce T. Hope, ${ }^{1}$ \\ and Yavin Shaham ${ }^{1}$ \\ ${ }^{1}$ Intramural Research Program, National Institutes of Health/National Institute on Drug Abuse, Baltimore, Maryland 21224, and ${ }^{2}$ Stanford University, Palo \\ Alto, California 94305
}

Relapse to maladaptive eating habits during dieting is often provoked by stress. Recently, we identified a role of dorsal medial prefrontal cortex (mPFC) neurons in stress-induced reinstatement of palatable food seeking in male rats. It is unknown whether endogenous neural activity in dorsal mPFC drives stress-induced reinstatement in female rats. Here, we used an optogenetic approach, in which female rats received bilateral dorsal $\mathrm{mPFC}$ microinjections of viral constructs coding light-sensitive eNpHR3.0-eYFP or control eYFP protein and intracranial fiber optic implants. Rats were food restricted and trained to lever press for palatable food pellets. Subsequently, pellets were removed, and lever pressing was extinguished; then the effect of bilateral dorsal mPFC light delivery on reinstatement of food seeking was assessed after injections of the pharmacological stressor yohimbine (an $\alpha-2$ andrenoceptor antagonist) or pellet priming, a manipulation known to provoke food seeking in hungry rats. Dorsal mPFC light delivery attenuated yohimbine-induced reinstatement of food seeking in eNpHR3.0-injected but not eYFP-injected rats. This optical manipulation had no effect on pellet-priming-induced reinstatement or ongoing food-reinforced responding. Dorsal mPFC light delivery attenuated yohimbine-induced Fos immunoreactivity and disrupted neural activity during in vivo electrophysiological recording in awake rats. Optical stimulation caused significant outward currents and blocked electrically evoked action potentials in eNpHR3.0-injected but not eYFP-injected mPFC hemispheres. Light delivery alone caused no significant inflammatory response in mPFC. These findings indicate that intracranial light delivery in eNpHR3.0 rats disrupts endogenous dorsal mPFC neural activity that plays a role in stress-induced relapse to food seeking in female rats.

\section{Introduction}

Although many people attempt to control their excessive food intake through dieting, they typically relapse to unhealthy eating habits within a few months (Kramer et al., 1989; Peterson and Mitchell, 1999). This relapse is often induced by stress and anxiety states (Grilo et al., 1989; Polivy and Herman, 1999). We have adapted the rat reinstatement model, commonly used to study relapse to abused drugs (Shaham et al., 2003), to investigate mechanisms underlying stress-induced relapse to food seeking during dieting (Ghitza et al., 2006).

Received April 25, 2012; revised 0ct. 4, 2012; accepted 0ct. 11, 2012.

Author contributions: D.J.C., B.K.H., B.T.H., and Y.S. designed research; D.J.C., A.B.K., N.J.M., B.M.N., M.J.H., B.C., H.-J.Y., J.M.B., and B.K.H. performed research; G.S., K.D., B.K.H., and B.T.H. contributed unpublished reagents/ analytic tools; D.J.C., A.B.K., N.J.M., J.M.B., and Y.S. analyzed data; D.J.C. and Y.S. wrote the paper.

This work was supported by the Intramural Research Program of the National Institute on Drug Abuse. We thank Drs. Peter Kalivas, Luis De Lecea, Kafui Dzirasa, and Garret Stuber for their technical guidance in applying the optogenetic technique to the present study.

The authors declare no competing financial interests.

Correspondence should be addressed to either Donna Calu or Yavin Shaham, Intramural Research Program, National Institutes of Health/National Institute on Drug Abuse, 251 Bayview Boulevard, Baltimore, MD 21224, E-mail: donna.calu@nih.gov or yshaham@intra.nida.nih.gov.

DOI:10.1523/JNEUROSCI.2016-12.2013

Copyright $\odot 2013$ the authors $\quad 0270-6474 / 13 / 330214-13 \$ 15.00 / 0$
Yohimbine is an $\alpha-2$ andrenoceptor antagonist that induces stress- and anxiety-like states in humans and nonhumans (Bremner et al., 1996a,b) and reliably reinstates food and drug seeking in male and female rats (Shepard et al., 2004; Nair et al., 2009; See and Waters, 2010; Pickens et al., 2012). In female rats, the effect of yohimbine on reinstatement of food seeking is independent of fluctuations in ovarian hormones and is similar in magnitude to that of males (Cifani et al., 2012; Pickens et al., 2012). In a recent study using male rats, we identified a causal role for $\mathrm{D}_{1}$ dopamine receptors in the dorsal medial prefrontal cortex (mPFC) for yohimbine-induced reinstatement of food seeking (Nair et al., 2011); dorsal mPFC refers herein to cingulate cortex area 1 and dorsal prelimbic areas of the mPFC (Paxinos and Watson, 2005). It is currently unknown whether dorsal mPFC neuronal activity plays a causal role in stress-induced reinstatement in female rats. There is a critical need to examine mechanisms of relapse to food seeking in female rats, because the proportion of women who use dietary supplements and seek dietary treatment is more than twice that of men (Davy et al., 2006; Pillitteri et al., 2008). Using female $c$-fos-GFP transgenic rats, we recently found that yohimbine-induced reinstatement of food seeking is associated with altered glutamatergic synaptic plasticity selectively in dorsal 
mPFC neurons that were activated by yohimbine (Cifani et al., 2012). These correlative findings have prompted us to use an optogenetic approach (Boyden et al., 2005; Zhang et al., 2007a; Tye and Deisseroth, 2012) to determine whether neuronal activity in dorsal mPFC plays a causal role in stress-induced reinstatement in female rats. We use a neuronal silencing strategy in which we used adeno-associated virus (AAV)-mediated gene transfer to transfect dorsal mPFC neurons with microbial light-sensitive protein, enhanced Natronomonas pharaonis halorhodopsin (eNpHR), which is a light-sensitive electrogenic $\mathrm{Cl}^{-}$pump that hyperpolarizes transfected neurons when activated by $\sim 590 \mathrm{~nm}$ yellow light (Han and Boyden, 2007; Zhang et al., 2007b; Gradinaru et al., 2008; Zhao et al., 2008). Recently, a similar optogenetic approach has been used to study the role of dorsal mPFC in reinstatement of cocaine seeking (Stefanik et al., 2012).

Here, we first addressed the concern that intracranial light delivery alone causes inflammatory responses in dorsal $\mathrm{mPFC}$ that could confound the interpretation of behavioral results after optogenetic stimulation. We then investigated whether optical stimulation of dorsal mPFC expressing eNpHR3.0 reduces endogenous and stress-induced neuronal activity, as assessed by slice electrophysiology, in vivo electrophysiology in awake rats, and Fos immunohistochemistry. Subsequently, we examined the effect of optically inhibiting dorsal mPFC on yohimbine-induced reinstatement of food seeking. Finally, to examine the specificity of the optogenetic manipulation on yohimbine-induced reinstatement, we tested the effect of dorsal mPFC optical inhibition on ongoing food self-administration and pellet-priming-induced reinstatement.

\section{Materials and Methods}

\section{Subjects and apparatus}

Female Long-Evans (total $n=86$ ) rats (National Institute on Drug Abuse breeding program or Charles River Laboratories; $15-16$ weeks old at the time of surgery) were maintained on a reverse $12 \mathrm{~h}$ light/dark cycle (lights off at 7:30 or 8:00 A.M.). All rats were individually housed after surgical procedures. For experiments $1-4$, rats had ad libitum access to Purina rat chow and water. For behavioral experiments (experiment 5-7), rats were weighed daily and food restricted to $9 \mathrm{~g} / \mathrm{d}$ Purina rat chow ( $\sim 55-65 \%$ of their daily food intake) during the training phase and $14-16 \mathrm{~g} / \mathrm{d}$ (to maintain stable body weight) during the extinction and reinstatement test phases; the rat chow was given after the daily behavioral sessions. All procedures followed the guidelines outlined in the National Institutes of Health Guide for the Care and Use of Laboratory Animals (eighth edition; http:/grants.nih.gov/grants/ olaw/Guide-for-the-Care-and-Use-of-Laboratory-Animals.pdf). A total of 18 rats were excluded because of fiber optic placement outside the dorsal mPFC $(n=4)$, poor laser performance during critical test $(n=1)$, poor bilateral expression of viral constructs $(n=5)$, significant viral expression outside the dorsal $\operatorname{mPFC}(n=3)$, lost head caps or illness $(n=4)$, and failure to meet an extinction criteria $(n=1)$.

Behavioral experiments were conducted in standard self-administration chambers (Med Associates). Each chamber had two levers $9 \mathrm{~cm}$ above the floor, but only one lever (the "active," retractable lever) activated the pellet dispenser, which delivered $45 \mathrm{mg}$ food pellets containing 12.7\% fat, $66.7 \%$ carbohydrate, and $20.6 \%$ protein (catalog \#1811155; Test Diet). This pellet type was chosen based on pellet preference tests in food-restricted female rats, using six pellet types (obtained from TestDiet and Bioserv) with different compositions of fat ( $0-35 \%)$ and carbohydrate (45-91\% sugar pellets) and different flavors (no flavor, banana, chocolate, grape).

\section{Construct and $A A V$ preparation}

The AAV packaging plasmids pAAV-CaMKII $\alpha$-eYFP and pAAVCaMKII $\alpha-$ eNpHR3.0-eYFP (Tye et al., 2011) were provided by K.D. AAV vector stocks were prepared by the National Institute on Drug Abuse/Intramural Research Program Optogenetic and Transgenic Tech- nology Core facility, using the modified triple-transfection method (Xiao et al., 1998; Howard et al., 2008). Briefly, 20 15-cm dishes containing HEK 293 cells at $85-95 \%$ confluency were transfected by $\mathrm{CaCl}_{2}$ method with pHelper (Stratagene), pAAV-CaMKIIa-eYFP and pAAV-CaMKIIaeNpHR3.0-eYFP, and pXR1 aka pXX12 (Rabinowitz et al., 2002), a plasmid containing rep/cap (replication/capsid) genes for serotype 1. Approximately $48 \mathrm{~h}$ after transfection, cells were harvested, lysed by freeze-thaw, and purified by centrifugation on $\mathrm{CsCl}$ gradient followed by fractionation. Final samples were dialyzed in PBS, aliquoted, and stored at $-80^{\circ} \mathrm{C}$ until use. AAV vector titers were $1-2 \times 10^{11} \mathrm{vg} / \mathrm{ml}$ as determined by quantitative PCR, using eYFP as the target sequence (Howard et al., 2008).

\section{Drugs}

Yohimbine hydrochloride was purchased from Sigma, dissolved in sterile water, and injected at a volume of $0.5 \mathrm{ml} / \mathrm{kg}$. The yohimbine dose is based on our previous studies (Ghitza et al., 2006; Nair et al., 2011; Pickens et al., 2012).

\section{Surgical procedures}

Rats in experiments 1, 2, and 4-6 were anesthetized with $100 \mathrm{mg} / \mathrm{kg}$ ketamine plus $10 \mathrm{mg} / \mathrm{kg}$ xylazine and were placed in the stereotaxic frame (David Kopf Instruments). Rats in experiment 3 were anesthetized with intraperitoneal injections of a mixture of sodium pentobarbital and chloral hydrate ( 60 and $25 \mathrm{mg} / \mathrm{kg}$ ) before surgery.

Viral injection. Microinjection needles (Hamilton syringe, $10 \mu \mathrm{l}$ with 30 gauge needle) were secured in stereotaxic pumps (UMP4 injector; World Precision Instruments) and inserted bilaterally in experiments 2 and $4-6$ or unilaterally in experiment 3 (in vivo electrophysiology), into the dorsal $\mathrm{mPFC}$ [coordinates from bregma: $+2.5 \mathrm{~mm}$ anteroposterior (AP), $\pm 1.2 \mathrm{~mm}$ mediolateral (ML) (at $10^{\circ}$ angle), and $-3.4 \mathrm{~mm}$ dorsoventral (DV)]; these coordinates are based on our previous study in male rats (Bossert et al., 2011, 2012; Nair et al., 2011) and pilot surgeries in female rats. A total volume of $0.7 \mu \mathrm{l}$ of either AAV1-CaMKII $\alpha-$ eYFP or AAV1-CaMKII $\alpha-$ eNpHR3.0-eYFP was injected at a rate of either 0.25 $\mu \mathrm{l} / \mathrm{min}$ (for in vivo electrophysiology) or $0.5 \mu \mathrm{l} / \mathrm{min}$ (for all other experiments). The microinjector needle was left in place for $3 \mathrm{~min}$, raised 0.1 $\mathrm{mm}$, and left in place $2 \mathrm{~min}$ before being removed from the brain. Rats were then removed from the stereotaxic frame and either sutured (if receiving viral injection only) or placed in a different stereotaxic frame for either chronic fiber optic implantation or optrode implantation (below).

Chronic intracranial fiber optic implantation. In experiments 1 and $4-6$, precalibrated fiber optics ( $200 \mu \mathrm{m}$ core fiber optic; Thorlabs) with $2.5 \mathrm{~mm}$ stainless steel ferrule (Fiber Instruments) were inserted bilaterally $0.5 \mathrm{~mm}$ above the site of the viral injections in the dorsal mPFC [coordinates from bregma: $+2.5 \mathrm{~mm} \mathrm{AP}, \pm 1.2 \mathrm{~mm} \mathrm{ML}$ (at $10^{\circ}$ angle), and $-2.9 \mathrm{~mm} \mathrm{DV}$ ] and were secured to the skull using jewelers screws and dental cement (Geristore; DenMat).

Chronic intracranial optrode implantation. In experiment 3, a drivable cannula housing a precalibrated fiber optic assembly $(100 \mu \mathrm{m}$ core; Doric Lenses) set 200-500 $\mu \mathrm{m}$ above a bundle of eight microelectrode wires (25 $\mu \mathrm{m}$ diameter iron-nickel-chromium wires; A-M Systems) was inserted into the dorsal mPFC [coordinates from bregma: $+2.5 \mathrm{~mm} \mathrm{AP}$, $\pm 1.2 \mathrm{~mm} \mathrm{ML}$ (at $10^{\circ}$ angle), and $\left.-2.4 \mathrm{DV}\right]$. The chronic optrode was secured to the skull using jeweler's screws and dental cement. Before implantation, the microwires were freshly cut with surgical scissors to extend $\sim 0.2-0.5 \mathrm{~mm}$ beyond the fiber optic and $\sim 1 \mathrm{~mm}$ beyond the cannula and electroplated with platinum $\left(\mathrm{H}_{2} \mathrm{PtCl}_{6}\right.$; Aldrich) to an impedance of $\sim 300 \mathrm{k} \Omega$. After each recording session, the optrode was advanced in $40-80 \mu \mathrm{m}$ increments to acquire new single-unit activity.

\section{Electrophysiology (ex vivo)}

Rats were anesthetized with $40 \mathrm{mg} / \mathrm{kg}$ pentobarbital (intraperitoneally) and transcardially perfused with $\sim 30 \mathrm{ml}$ of nearly frozen $\left(\sim 0^{\circ} \mathrm{C}\right)$ modified artificial CSF (aCSF) at a rate of $\sim 20 \mathrm{ml} / \mathrm{min}$. The modified aCSF for perfusion contained the following (in $\mathrm{mm}$ ): 225 sucrose, $119 \mathrm{NaCl}, 2.5$ $\mathrm{KCl}, 1.0 \mathrm{NaH}_{2} \mathrm{PO}_{4}, 4.9 \mathrm{MgCl}_{2}, 0.1 \mathrm{CaCl}_{2}, 26.2 \mathrm{NaHCO}_{3}$, and 1.25 glucose. After perfusion, the brain was quickly removed and placed into ice-cold aCSF for 1-2 min. Coronal sections of the $\mathrm{mPFC}(250 \mu \mathrm{m})$ were prepared with VT-1200 vibratome (Leica). Slices were placed in a hold- 
ing chamber (containing aCSF with $1 \mathrm{~mm}$ ascorbic acid added 15 min before brain dissection) and allowed to recover for at least $30 \mathrm{~min}$ before being placed in the recording chamber and superfused with a bicarbonatebuffered solution saturated with $95 \% \mathrm{O}_{2}$ and $5 \% \mathrm{CO}_{2}$ and containing the following (in mM): $119 \mathrm{NaCl}, 2.5 \mathrm{KCl}, 1.0 \mathrm{NaH}_{2} \mathrm{PO}_{4}, 1.3 \mathrm{MgCl}_{2}, 2.4 \mathrm{CaCl}_{2}$, $26.2 \mathrm{NaHCO}_{3}$, and 11 glucose (at $32-34^{\circ} \mathrm{C}$ ).

\section{Recording (ex vivo)}

Picrotoxin $(50 \mu \mathrm{M})$ and CNQX $(10 \mu \mathrm{M})$ were present throughout the experiment to block inhibitory and excitatory synaptic transmission, respectively. Cells were visualized using infrared differential interference contrast video microscopy. Whole-cell current-clamp recordings were made using a MultiClamp 700B amplifier (Molecular Devices). Electrodes $(2.8-4.0 \mathrm{M} \Omega)$ contained the following: $140 \mathrm{~mm}$ potassium methane sulfonate, $10 \mathrm{~mm}$ HEPES, $0.05 \mathrm{~mm}$ EGTA, $5 \mathrm{~mm} \mathrm{~K}-\mathrm{Cl}, 2 \mathrm{~mm} \mathrm{MgCl}$, $2 \mathrm{~mm} \mathrm{Na}_{2}$ GTP, $0.4 \mathrm{~mm}$ NaGTP, 1\% biocytin, pH 7.2-7.3, $280 \mathrm{mOsm}$. Series resistance $(10-40 \mathrm{M} \Omega)$ was continually monitored online with a $-20 \mathrm{pA}, 300 \mathrm{~ms}$ current injection given after every current injection step; if the series resistance changed by $>20 \%$, data were not included in the analysis. Membrane potentials were not corrected for junction potentials (estimated to be $10 \mathrm{mV}$ ). Resting membrane potentials were determined immediately after breaking into the neuron. Membrane potential was then set to $-80 \mathrm{mV}$ by injecting direct current through patch amplifier. To determine the input resistance, hyperpolarizing current injections were injected into the cell. Input resistance was taken at the linear part of the trace. For evaluation of light-evoked currents, neurons were voltage clamped at $-70 \mathrm{mV}$ and a $200 \mathrm{~ms}$ light pulse $(>20 \mathrm{~mW})$ of either 532 or $593.5 \mathrm{~nm}$ delivered via a $200 \mu \mathrm{m}$ optical fiber coupled to either a 532 or $593.5 \mathrm{~nm}$ solid-state laser (OEM Laser Systems). To evaluate the effect of eNpHR3.0-mediated currents on neuronal firing in the mPFC, $200 \mathrm{~ms}$ pulses of either 532 or $593.5 \mathrm{~nm}$ light $(>20 \mathrm{~mW})$ were applied during direct current injections in a subset of neurons. Data were acquired at 20 $\mathrm{kHz}$ and filtered at 2 or $10 \mathrm{kHz}$ using Clampex10.2 software (Molecular Devices).

\section{Electrophysiology (in vivo): optrode recording in awake rats}

Optical stimulation and single-unit recording. Three to 8 weeks after surgery, rats were brought to the recording box and connected to a recording cable (Plexon) coupled with a fiber optic patch cable (Doric Lenses). Neural activity was recorded using 16 channel Omniplex System (Plexon), interfaced with a Master-9 Pulse Stimulator (A.M.P.I.), which also controlled a DPSS $593.5 \mathrm{~nm}$ laser system (OEM Laser Systems) used for intracranial light delivery. Fiber optic output was precalibrated to $4-8 \mathrm{~mW}$ from the fiber tip before implantation, and the laser was recalibrated to this power output using an ex vivo power-matched fiber optic before stimulation/recording sessions. Wires were screened for activity daily; if no activity was detected, the rat was removed, and the electrode assembly was advanced 40 or $80 \mu \mathrm{m}$. Otherwise, active wires were selected to be recorded, a stimulation session was conducted (detailed below in experiment 3 ), and the electrode was advanced at the end of the session.

Signals from the electrode wires were amplified $20 \times$ by an operational amplifier head stage (HST/8o50-G20; Plexon), located on the recording cable that connected directly to the electrode array. Immediately outside the chamber, the signals were passed through a differential preamplifier, in which the wide-band signal was filtered at $0.5-8000 \mathrm{~Hz}$. The wideband signal was then sent to the Omniplex chassis, in which it was amplified at $250-1000 \times$ and digitized at $40 \mathrm{kHz}$. After digitization, the wide-band signal was further filtered at $300-8000 \mathrm{~Hz}$ and thresholded into a spike waveform segment. Waveforms ( $>2.5$ :1 signal-to-noise) were extracted from active channels and recorded to disk by an associated workstation with event timestamps from the stimulator driving laser light delivery. Waveforms were not inverted before data analysis.

In vivo neural data analyses. Units were sorted using Offline Sorter software (Plexon), using a template matching algorithm. Sorted files were then processed in Neuroexplorer to extract unit timestamps and relevant stimulation event markers. These data were subsequently analyzed in MATLAB. Paired $t$ tests were used to measure within-cell differences in firing rate $(p<0.05)$ during epochs of interest. Bonferroni's correction was used to account for multiple comparisons in the analyses of population data.

\section{Histology}

The rats were deeply anesthetized with isoflurane $(\sim 80 \mathrm{~s})$ and perfused transcardially with $100 \mathrm{ml}$ of $0.1 \mathrm{M}$ PBS, followed by $400 \mathrm{ml}$ of $4 \%$ paraformaldehyde in $0.1 \mathrm{M}$ sodium phosphate, $\mathrm{pH}$ 7.4. Brains were removed and postfixed in $4 \%$ paraformaldehyde for $2 \mathrm{~h}$ before transfer to $30 \%$ sucrose in $0.1 \mathrm{~m}$ sodium phosphate, $\mathrm{pH} 7.4$, for $48 \mathrm{~h}$ at $4^{\circ} \mathrm{C}$. Brains were subsequently frozen in powdered dry ice and stored at $-80^{\circ} \mathrm{C}$ until sectioning. Coronal sections ( 30 or $40 \mu \mathrm{m}$ ) containing dorsal and ventral mPFC (approximately +2.2 to $3.5 \mathrm{~mm}$ from bregma) were cut using a cryostat (Leica Microsystems), collected in cryoprotectant (20\% glycerol and $2 \%$ DMSO in $0.1 \mathrm{~m}$ sodium phosphate, $\mathrm{pH} 7.4$ ), and stored at $-80^{\circ} \mathrm{C}$ until additional processing.

\section{Iba-1 and GFAP immunohistochemistry}

Rats were perfused as indicated above (see Histology). Paraformaldehydefixed brains were sectioned into $30 \mu \mathrm{m}$ sections on a Leica cryostat. Sections were collected into phosphate buffer (PB) [16.83 g of $\mathrm{NaH}_{2} \mathrm{PO}_{4}$ ( $140 \mathrm{~mm}$ ) plus $3.85 \mathrm{~g}$ of $\mathrm{NaOH}, \mathrm{H}_{2} \mathrm{O}$ to $1 \mathrm{~L}$ ], blocked with $4 \%$ BSA plus $0.3 \%$ Triton $\mathrm{X}-100$ (in $\mathrm{PB}$ ), and immunostained overnight at $4^{\circ} \mathrm{C}$ with monoclonal anti-GFAP (clone GA5, 1:300 dilution; Millipore) or polyclonal anti-Iba-1 (019-19741, 1:500 dilution; Wako Pure Chemicals). Alexa Fluor secondary antibodies (Invitrogen) against the appropriate species were used, and nuclei were stained with DAPI $(1 \mu \mathrm{g} / \mathrm{ml}$ in PB). Sections were mounted to glass slides with Mowiol 4-88 (EMD Chemicals), and images were captured on a Nikon AZ100M (CoolSnap HQ ${ }^{2}$ camera, $1 \times$ images) or Nikon Eclipse 80i (QImaging Retiga EXi camera, $10 \times$ images). For each rat, a single section containing fiber tracts (experiment 1) was selected for analysis. Regions of interest, encompassing the dorsal mPFC, were selected using Nikon Elements software, and the number of immunoreactive cells per square millimeter was quantified and analyzed using Prism (GraphPad Software).

\section{Fos immunohistochemistry}

Rats were perfused and tissue prepared as indicated above (see Histology). Immunohistochemical procedures were based on our previous studies (Koya et al., 2009; Nair et al., 2011; Bossert et al., 2012). Immunolabeling for Fos (the protein product of the immediate early gene c-fos) was used to identify and quantify Fos expression in dorsal mPFC neurons. Sections were thawed and washed three times for $10 \mathrm{~min}$ in $0.1 \mathrm{M}$ PBS, incubated for $1 \mathrm{~h}$ in $3 \%$ normal goat serum (NGS) in PBS with $0.25 \%$ Triton X-100 (PBS-Tx), and incubated overnight at $4^{\circ} \mathrm{C}$ with anti-Fos primary antibody (sc-52, lot I2209; Santa Cruz Biotechnology) diluted 1:4000 in 1\% NGS in PBS-Tx. Sections were then washed in PBS and incubated for $2 \mathrm{~h}$ with biotinylated anti-rabbit IgG secondary antibody (BA-1000; Vector Laboratories) diluted 1:600 in 1\% NGS in PBS-Tx. Sections were washed in PBS and incubated in avidin-biotin-peroxidase complex (ABC Elite kit, PK-6100; Vector Laboratories) in PBS containing $0.5 \%$ Triton X-100 for $1 \mathrm{~h}$ and washed in PBS. Sections were developed in 3,3'-diaminobenzidine for $\sim 1-4 \mathrm{~min}$, washed in PBS, mounted onto chromium-potassium sulfate (chrom-alum)/gelatin-coated slides, and air dried overnight. The slides were dehydrated through a graded series of alcohol $(30,60,90,95,100,100 \%$ ethanol), cleared with Citrasolv (Thermo Fisher Scientific), and coverslipped with Permount (Sigma). Bright-field images of the dorsal mPFC were digitally captured using a CCD Camera (Coolsnap; Photometrics, Roper Scientific) attached to a Carl Zeiss Axioskop 2 microscope with a $5 \times$ (quantification) or $10 \times$ (figure) objective. Labeled Fos-immunoreactive nuclei in two sections (containing fiber tracts) of each left and right hemisphere from each rat were automatically counted using IPLab software (version 3.9.4 r5 for Macintosh; Scanalytics), and the number of immunoreactive cells per square millimeter was quantified. Image capture and quantification of Fos-immunoreactive nuclei were conducted by D.J.C. and A.B.K. in a blind manner.

\section{Verification of virus expression and intracranial fiber optic or optrode placement}

Fluorescent images of dorsal mPFC were captured with QImaging Exi Aqua camera attached to a Carl Zeiss Axioskop 2 microscope using a $5 \times$ 
or $10 \times$ objective. Rats that had insufficient bilateral expression of eYFP ventral to the fiber tip in dorsal $\mathrm{mPFC}$ or rats that had fiber optics that were outside the area of dorsal mPFC expression were excluded. Rats that had bilateral eYFP expression that extended into ventral mPFC were also excluded.

\section{NeuN and GFAP immunohistochemistry}

Rats were perfused and tissue prepared as indicated above (see Histology). To confirm that expression of eNpHR3.0-eYFP was primarily in neurons of the dorsal mPFC, we used NeuN, a marker for neuronalspecific nuclear protein (Mullen et al., 1992). We determined the proportion of eNpHR3.0-eYFP-expressing cells that were neurons $\sim 2$ weeks after viral injection (ideal time point for visualizing eNpHR3.0eYFP expression in cell bodies). Six sections containing dorsal mPFC from three rats were thawed and washed (three times for $10 \mathrm{~min}$ each) in Tris-buffered saline (TBS) $(0.025 \mathrm{M}$ Tris- $\mathrm{HCl}, 0.5 \mathrm{M} \mathrm{NaCl}, \mathrm{pH} 7.5)$ and incubated for $20 \mathrm{~min}$ in TBS with $0.2 \%$ Triton X-100 (TBS-Tx). Sections were washed in TBS and incubated for $48 \mathrm{~h}$ with mouse anti-NeuN primary antibody (1:2000 dilution of MAB377; Millipore) in TBS-Tx. Sections were again washed in TBS and incubated for $1 \mathrm{~h}$ with secondary Alexa Fluor 568-labeled goat anti-mouse antibody (1:200 dilution in TBS-Tx; Invitrogen), and nuclei were stained with DAPI $(1 \mu \mathrm{g} / \mathrm{ml}$ in TBS). Finally, sections were washed in TBS, mounted on chrom-alum/ gelatin-coated slides, air dried, and coverslipped with Mowiol fluorescent mounting medium.

To further confirm that expression of eNpHR3.0-eYFP expression was primarily in mPFC neurons, we used GFAP to determine the proportion of eNpHR3.0-eYFP-expressing cells that were astrocytes; the assay was performed $\sim 2$ weeks after viral injection. Six brain sections containing dorsal $\mathrm{mPFC}$ from three rats were thawed and washed with $\mathrm{PB}$ [16.83 $\mathrm{g}$ of $\mathrm{NaH}_{2} \mathrm{PO}_{4}(140 \mathrm{~mm})$ plus $3.85 \mathrm{~g}$ of $\mathrm{NaOH}, \mathrm{H}_{2} \mathrm{O}$ to $1 \mathrm{~L}$ ] two times, then blocked with $4 \%$ BSA plus $0.3 \%$ Triton X-100 (in PB), and immunostained overnight at $4^{\circ} \mathrm{C}$ with monoclonal anti-GFAP (clone GA5, 1:300 dilution; Millipore). Alexa Fluor secondary antibodies (Invitrogen) against the appropriate species were used, and nuclei were stained with DAPI $(1 \mu \mathrm{g} / \mathrm{ml}$ in PB).

Fluorescent images of dorsal mPFC were captured with QImaging Exi Aqua camera attached to a Carl Zeiss Axioskop 2 microscope using a $40 \times$ objective. One to two dorsal mPFC $40 \times$ images were taken per hemisphere across two sections per rat, and the proportion of eNpHR3.0eYFP-positive cells that were NeuN-labeled or GFAP-labeled was quantified using iVision MacOS 10.62 (version 4.0.15) by D.J.C.

\section{Fos + CaMKII and Fos + GAD immunohistochemistry}

Two hours after a test for yohimbine-induced reinstatement, the rats were anesthetized and perfused, and their brains were removed and processed as described above (see Histology). We assessed the phenotype of Fos-expressing $\left(\mathrm{Fos}^{+}\right.$) neurons by double labeling for Fos and calcium/ calmodulin-dependent protein kinase II (CaMKII), a marker of cortical glutamatergic pyramidal projection neurons (Liu and Jones, 1996) and glutamic acid decarboxylase 67 (GAD67), a marker of GABAergic neurons (Kaufman et al., 1986, 1991).

Paraformaldehyde-fixed brains were sectioned into $30 \mu \mathrm{m}$ sections on a Leica cryostat. Sections were incubated for $1 \mathrm{~h}$ in a blocking solution (5\% NGS and $2.5 \%$ bovine serum albumin in PBS with $0.2 \%$ Triton $\mathrm{X}-100)$ and then incubated for $48 \mathrm{~h}$ with the anti-Fos primary antibody (rabbit, 1:400 dilution, sc-52; Santa Cruz Biotechnology) and either antiCaMKII primary antibody (mouse, 1:1000 dilution, MA1-048; Pierce Biotechnology) or anti-GAD67 primary antibody (mouse, 1:1000 dilution, MAB5406; Millipore) in blocking solution. After washing, sections were incubated for $2 \mathrm{~h}$ in blocking solution with secondary antibodies Alexa Fluor 488-labeled donkey anti-rabbit (1:200 dilution, A-21206; Invitrogen) and Alexa Fluor 568-labeled goat anti-mouse antibody (1: 200 dilution, A-11004; Invitrogen). Sections were then washed, mounted on chrom-alum/gelatin-coated slides, air dried, and coverslipped with Vectashield or mowiol fluorescent mounting medium. Fluorescent images of dorsal mPFC were captured with QImaging Exi Aqua camera attached to a Carl Zeiss Axioskop 2 microscope using a $40 \times$ objective.
One to two dorsal mPFC $40 \times$ images were taken per hemisphere across two sections per rat. The proportion of Fos ${ }^{+}$cells that were CaMKII labeled or GAD67 labeled was quantified using iVision MacOS 10.62 (version 4.0.15) by A.B.K.

\section{Specific experiments}

Experiment 1: effect of mPFC light delivery on astrocyte and microglia markers. In experiment 1 , we assessed whether continuous light stimulation caused cell inflammation or injury as assessed by astrocyte or microglia activation (summary in Table 1) (Kreutzberg, 1996; Ridet et al., 1997). For this purpose, we measured GFAP (a marker of astrocyte activation) and Iba-1 (a marker of microglia activation) $24 \mathrm{~h}$ after dorsal $\mathrm{mPFC}$ laser light delivery to naive rats (no viral injection). The naive rats $(n=8)$ received bilateral fiber optic implants (precalibrated to $20 \mathrm{~mW}$ light output from fiber tip) in the dorsal $\mathrm{mPFC}$ as described above. Two weeks after surgery, the rats were habituated to upcoming experimental manipulations in two to three sessions in which the rats were connected to a dummy patch cable system and were exposed to the behavioral chamber for 30-90 min. Three weeks after surgery, the rats were connected unilaterally (right fiber optic) to the laser via a fiber optic rotary joint/patch cable system (Doric Lenses) and intracranial laser light (593.5 $\mathrm{nm}$, recalibrated to $20 \mathrm{~mW}$ with power-matched fiber before testing) was delivered unilaterally using one of the following parameters: $30 \mathrm{~min}$ of con-

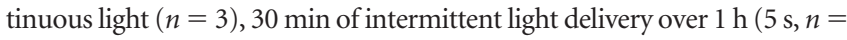
3 or 5 min, $n=2$ cycles). The contralateral hemisphere served as the withinsubject control for mechanical damage after fiber optic implant. After $24 \mathrm{~h}$, rats were killed, and inflammatory signaling and cell injury were examined by Iba-1 (microglia) and GFAP (astrocyte) immunoreactivity.

Experiment 2: effect of $m P F C$ light delivery on ex vivo neural activity. We examined the effect of 532 or $593.5 \mathrm{~nm}$ light delivery on ex vivo dorsal mPFC neuronal activity from rats $(n=5)$ injected unilaterally with AAV1-CaMKII $\alpha$-eYFP virus and contralaterally with the AAV1CaMKII $\alpha$-eNpHR3.0-eYFP virus. Six to 7 weeks after viral injection, rats were killed and prepared for electrophysiological recordings, which were conducted as described above. To examine whether the basic intrinsic properties of the cells were altered by the membrane expression of the eNpHR3.0 protein, we measured resting membrane potential and input resistance (eNpHR3.0, $n=9$; eYFP, $n=4$ cells). We also determined the ability of light to evoke outward hyperpolarizing currents and for those currents to block electrically evoked dorsal mPFC neuronal firing.

Experiment 3: effect of mPFC light delivery on in vivo single-unit neural activity in awake rats. We examined the effect of 593.5 light delivery on in vivo dorsal $\mathrm{mPFC}$ neuronal activity in rats injected unilaterally with the eNpHR3.0 construct. The rats $(n=3)$ received unilateral injections of AAV1-CaMKII $\alpha-\mathrm{eNpHR} 3.0-\mathrm{eYFP}$ and ipsilateral implantation of the chronic optrode recording device above the site of viral injection. Three to 8 weeks after surgery, rats were brought to the recording box and were connected to a recording cable (Plexon) coupled with a fiber optic patch cable (Doric Lenses). The recording/patch cable was connected to a hybrid electrical/optical rotary joint (Doric Lenses) or a two-part commutator system (electrical: Christ Instruments; optical: Doric Lenses) that allowed freedom of movement in the awake rat. Fiber optic output was precalibrated to $4-8 \mathrm{~mW}$ from the fiber tip before implantation, and the laser was recalibrated to this power output using a power-matched fiber optic before stimulation/recording sessions. Wires with detectable neural activity were selected to be recorded, and a stimulation session was conducted. To determine whether neurons were light sensitive, the laser was activated in $5 \mathrm{~s}$ ( 40 trials; $10 \mathrm{~s}$ intertrial interval), $2 \mathrm{~min}$ (five trials, $2 \mathrm{~min}$ intertrial interval), and/or $30 \mathrm{~min}$ (two trials, $30 \mathrm{~min}$ intertrial interval) cycles, and spontaneous activity of neurons was recorded during the light stimulation protocols. The optrode was advanced at the end of the session. Single-unit activity was analyzed as described above (see section In vivo neural data analyses).

Experiment 4: effect of $m P F C$ light delivery on yohimbine-induced Fos induction. We examined the effect of bilateral $593.5 \mathrm{~nm}$ intracranial light delivery on water (vehicle)-induced and yohimbine-induced mPFC neuronal activation (as assessed by Fos immunohistochemistry) in rats that received unilateral microinjection of the AAV1-CaMKII $\alpha$-eYFP con- 
Table 1. Overview of the experiments

\begin{tabular}{|c|c|c|c|}
\hline Experiment & $n$ (rats) & Surgical procedure & Experimental manipulation \\
\hline $\begin{array}{l}\text { 1: Effect of mPFC light delivery on } \\
\text { astrocyte and microglia markers }\end{array}$ & $\begin{array}{l}n=3 ; \text { continuous light } \\
n=3 ; \text { light cycles }(5 \mathrm{~s}) \\
n=2 ; \text { light cycles }(5 \mathrm{~min})\end{array}$ & $\begin{array}{l}\text { Bilateral: fiber optics implanted in dorsal } \\
\text { mPFC }\end{array}$ & $\begin{array}{l}\text { Unilateral: } 30 \text { min light delivery in vivo } \\
\text { Contralateral hemisphere: no light delivery } \\
\text { - Rats killed } 24 \mathrm{~h} \text { after stimulation for immunohistochemical } \\
\text { evaluation }\end{array}$ \\
\hline $\begin{array}{l}\text { 2: Effect of mPFC light delivery on } \\
\text { ex vivo neural activity }\end{array}$ & $n=5$ & $\begin{array}{l}\text { Unilateral: AAV-CaMKII } \alpha \text { - eYFP } \\
\text { Unilateral: AAV-CaMKII } \alpha \text { - eNpHR3.0 - eYFP }\end{array}$ & $\begin{array}{l}\text { Ex vivo (slice) electrophysiology in eNpHR3.0 and eYFP } \\
\text { hemispheres using the following: } \\
\text { - Voltage clamp plus light delivery: measure light-evoked } \\
\text { current } \\
\text { - Current injections plus light delivery: measure voltage } \\
\text { change in the presence and absence of light }\end{array}$ \\
\hline $\begin{array}{l}\text { 3: Effect of mPFC light delivery on } \\
\text { in vivo single-unit neural activity } \\
\text { in awake rats }\end{array}$ & $n=3$ & $\begin{array}{l}\text { Unilateral: AAV-CaMKII } \alpha \text { - eNpHR3.0 - eYFP } \\
\text { Ipsilateral: drivable recording optrode }\end{array}$ & $\begin{array}{l}\text { In vivo recording and light delivery in awake, freely moving rats } \\
\text { expressing eNpHR3.0 in dorsal mPFC. Record spontaneous } \\
\text { neuronal activity in response to the following: } \\
\text { - } 5 \text { s light cycles } \\
\text { - } 2 \text { min light cycles } \\
\text { - } 30 \text { min light cycles }\end{array}$ \\
\hline $\begin{array}{l}\text { 4: Effect of mPFC light delivery on } \\
\text { yohimbine-induced Fos induction }\end{array}$ & $\begin{array}{l}n=8 ; \text { water (i.p.) } \\
n=9 ; \text { yohimbine (i.p.) }\end{array}$ & $\begin{array}{l}\text { Unilateral: AAV-CaMKII } \alpha \text { - eYFP } \\
\text { Unilateral: AAV-CaMKII } \alpha \text { - eNpHR3.0- eYFP } \\
\text { Bilateral: fiber optics } 0.5 \mathrm{~mm} \text { above site } \\
\text { of viral injections }\end{array}$ & $\begin{array}{l}\text { In vivo bilateral light delivery in eNpHR3.0 and eYFP } \\
\text { hemispheres after the following: } \\
\text { - Water (i.p.) injections } \\
\text { - Yohimbine ( } 2 \mathrm{mg} / \mathrm{kg} \text {, i.p.) injections }\end{array}$ \\
\hline $\begin{array}{l}\text { 5: Effect of mPFC light delivery on } \\
\text { ongoing food self-administration }\end{array}$ & $\begin{array}{l}n=17 ; \mathrm{eYFP} \\
n=15 ; \text { eNpHR3.0 } \\
n=10 \text { from each group receive } \\
\quad \text { light manipulation }\end{array}$ & $\begin{array}{l}\text { Bilateral: AAV-CaMKII } \alpha \text {-eYFP } \\
\text { Or } \\
\text { Bilateral: AAV-CaMKII } \alpha-\text { eNpHR3.0-eYFP } \\
\text { And } \\
\text { Bilateral: fiber optics } 0.5 \mathrm{~mm} \text { above site of viral } \\
\quad \text { injections }\end{array}$ & $\begin{array}{l}\text { Food self-administration training, followed by within-subjects } \\
\text { food self-administration sessions with and without bilateral } \\
\text { light delivery } \\
\text { - Food self-administration alone } \\
\text { - Food self-administration plus light delivery }\end{array}$ \\
\hline $\begin{array}{l}\text { 6: Effect of mPFC light delivery on } \\
\text { reinstatement of food seeking }\end{array}$ & $\begin{array}{l}n=14 ; \mathrm{eYFP} \text { (from experiment } 5 \text { ) } \\
n=15 ; \mathrm{eNpHR3} .0 \text { (from } \\
\quad \text { experiment } 5 \text { ) }\end{array}$ & Same as experiment 5 & $\begin{array}{l}\text { Food self-administration training, extinction training, followed } \\
\text { by within-subjects reinstatement testing with and without } \\
\text { bilateral light delivery } \\
\text { - Pellet reinstatement } \\
\text { O No pellet } \\
\circ \text { Pellet } \\
\circ \text { Pellet plus light } \\
\circ \text { Light alone } \\
\text { - Yohimbine reinstatement } \\
\circ \text { Vehicle } \\
\circ \text { Yohimbine } \\
\bigcirc \text { Yohimbine plus light } \\
\circ \text { Vehicle plus light }\end{array}$ \\
\hline $\begin{array}{l}\text { 7: Phenotypic characterization } \\
\text { of mPFC neurons activated by } \\
\text { yohimbine during a reinstatement } \\
\text { test }\end{array}$ & $n=8$ & None & $\begin{array}{l}\text { Food self-administration training, extinction training, followed } \\
\text { by yohimbine-induced reinstatement testing } \\
\text { - Rats killed } 2 \mathrm{~h} \text { after yohimbine injection for } \\
\text { immunohistochemical double-labeling assays }\end{array}$ \\
\hline
\end{tabular}

struct into dorsal mPFC and unilateral microinjection of the AAV1CaMKII $\alpha-$ eNpHR3.0-eYFP construct into the contralateral side, as well as bilateral fiber optic implants above the site of viral injection. Four to 5 weeks after surgery, the rats were habituated to upcoming experimental manipulations in two to three sessions in which they received sham water (vehicle) injections, were connected to a dummy patch cable system, and were exposed to the behavioral chamber for 30-90 min. Five to 6 weeks after surgery, in a single session, rats received either vehicle $(n=8)$ or yohimbine injections $(2 \mathrm{mg} / \mathrm{kg}$, i.p. $)(n=9)$ and were immediately connected bilaterally to the laser via a fiber optic rotary joint/ patch cable system (Doric Lenses), and intracranial laser light (90 min continuous, $593.5 \mathrm{~nm}$, recalibrated to $4-8 \mathrm{~mW}$ with power-matched fiber before testing) was delivered bilaterally. The laser was turned off, and the rats were disconnected from the laser patch cable $90 \mathrm{~min}$ after the injection. Two hours after the injection, rats were anesthetized and perfused, their brains were removed, and tissue was subsequently processed for Fos immunohistochemistry as described above. We delivered intracranial light for a longer duration $(90 \mathrm{~min})$ than that used in our behavioral experiments, because yohimbine-induced mPFC neuronal activation lasts for at least $6 \mathrm{~h}$ (Cifani et al., 2012). The rats were anesthetized and perfused $2 \mathrm{~h}$ after yohimbine injections, because Fos induction is often maximal at this time point after neuronal activation (Morgan and Curran, 1991).

Experiment 5: effect of $m P F C$ light delivery on ongoing food selfadministration. We examined the effect of bilateral $593.5 \mathrm{~nm}$ intracranial light delivery on ongoing food self-administration in rats that underwent surgery to inject either the AAV1-CaMKII $\alpha$-eYFP virus $(n=17)$ or the AAV1-CaMKII $\alpha$-eNpHR3.0-eYFP virus $(n=15)$ bilaterally into the dorsal $\mathrm{mPFC}$ and to chronically implant fiber optics above the injection sites. Fiber optic output was precalibrated to $4-8 \mathrm{~mW}$ from the fiber tip before implantation, and the laser was recalibrated to this power output using a power-matched fiber optic before behavioral testing sessions. The training conditions were similar to those used in our previous studies (Nair et al., 2011; Pickens et al., 2012). Briefly, we gave the rats $3 \mathrm{~h}$ "autoshaping" sessions for 2 or $3 \mathrm{~d}$, during which pellets were delivered noncontingently every $5 \mathrm{~min}$ into a receptacle located near the active 
A Effect of intracranial light delivery on markers of tissue damage

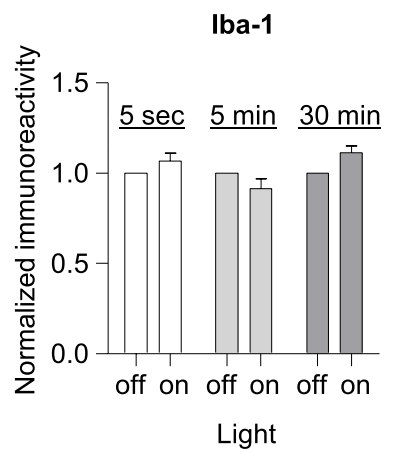

GFAP

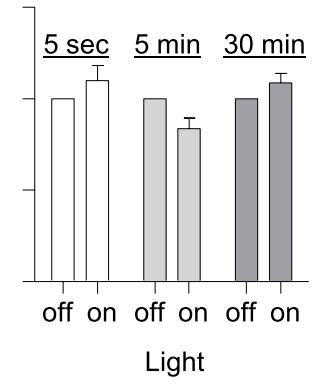

B Example of GFAP or lba-1 immunoreactivity in the dorsal mPFC

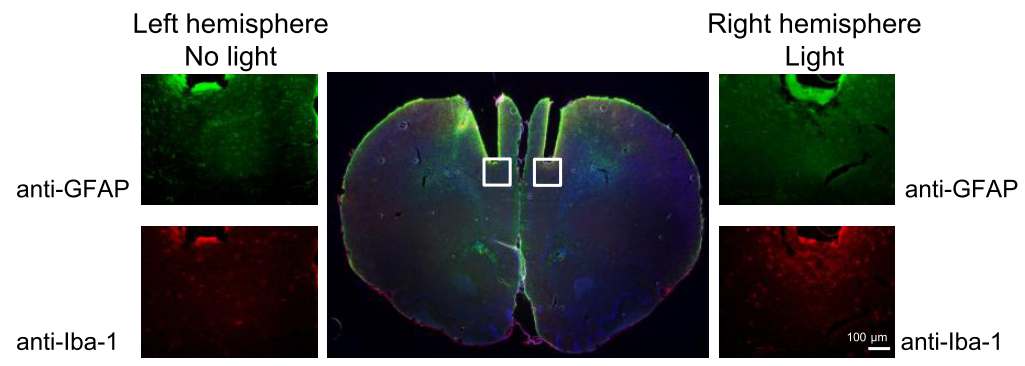

Figure 1. Intracranial light delivery and viral expression did not alter GFAP or Iba-1 immunoreactivity in the dorsal mPFC. $\boldsymbol{A}$, Densitometric analysis of $\mathrm{Iba}-1$ and GFAP immunoreactivity in the dorsal $\mathrm{mPFC}$. All rats received $30 \mathrm{~min}$ of intracranial light delivery $(593.5 \mathrm{~nm}, 20 \mathrm{~mW}$ ), either as on/off cycles ( $5 \mathrm{~s}$ and $5 \mathrm{~min}$ ) or as constant light (30 min). Immunoreactivity in the light-exposed hemisphere was compared with the control hemisphere (normalized to 1 ) for each rat. $\boldsymbol{B}$, Representative immunohistochemical staining of astrocytes (GFAP) and microglia (Iba-1) in light-exposed (right) and control (left) hemispheres. 10X images correspond to the boxed areas of the central $1 \times$ image. Scale bar, $100 \mu \mathrm{m}$.

lever. Pellet delivery was accompanied by a compound $5 \mathrm{~s}$ tone-light cue, both of which were located above the active lever. Subsequently, we trained the rats to self-administer the pellets on a fixed-ratio- 1 (FR-1), 20-s timeout reinforcement schedule. At the start of each $3 \mathrm{~h}$ session, the red house light was turned on, and the active lever was extended. Reinforced active lever presses resulted in the delivery of one pellet, accompanied by the compound $5 \mathrm{~s}$ tone-light cue. Rats underwent 10-11 training sessions under these conditions. A subset of the rats in the eYFP $(n=10)$ and eNpHR3.0 $(n=10)$ groups were tested with intracranial light delivery $(593.5 \mathrm{~nm}, 4-8 \mathrm{~mW}$, first 30 min continuous) during a single training session (between sessions 7 and 10), and responding during the first $30 \mathrm{~min}$ of this session was compared with responding during the first $30 \mathrm{~min}$ of the following session in which intracranial light was not delivered.

Experiment 6: effect of $m P F C$ light delivery on reinstatement of food seeking. We used the same rats as above [two groups of rats: eYFP virus $(n=14)$ and eNpHR3.0 virus $(n=15)$ ] to examine the effect of bilateral $593.5 \mathrm{~nm}$ intracranial light delivery on yohimbine- and pellet-priming-induced reinstatement of food seeking. After 10-11 3-h food self-administration training sessions, all rats underwent extinction sessions that were identical to the training sessions, except that presses on the active lever were not reinforced with a food pellet. The rats were given 11-29 extinction sessions until they reached an extinction criterion (mean active lever responding across the last three extinction sessions of $<20 \%$ of extinction day 1 responding). Rats that did not reliably extinguish lever responding during the regular $3 \mathrm{~h}$ sessions were given four to eight sessions comprising three $1 \mathrm{~h}$ mini-sessions, separated by $5 \mathrm{~min}$ with the house light off and lever retracted. We then assessed the effect of intracranial light delivery on yohimbine-induced- and pellet-priming-induced reinstatement during $30 \mathrm{~min}$ (pellet) or $1 \mathrm{~h}$ (yohimbine) sessions. The rats received either water (vehicle) or yohimbine injections $(2 \mathrm{mg} / \mathrm{kg}$, i.p.) 30-40 $\mathrm{min}$ before the start of the test sessions or received four pellets at the beginning of the test session in a counterbalanced order.
Each test condition was performed with intracranial light delivery [593.5 $\mathrm{nm}, 4-8 \mathrm{~mW}$, 30 -min continuous (pellet) or $1 \mathrm{~h}$ continuous (yohimbine)] or without light delivery [30 min (pellet) or $1 \mathrm{~h}$ (yohimbine)] in a counterbalanced order. Each rat underwent at least one yohimbine-free and pellet-free extinction session between each test session. Data from the first 30 min of the $1 \mathrm{~h}$ yohimbine sessions were used in the statistical analysis to allow for statistical comparisons with the control condition of $30 \mathrm{~min}$ light stimulation after vehicle injections and the $30 \mathrm{~min}$ pellet-priming manipulation. As described in Results for the 30 min data point, the 60 min light stimulation significantly inhibited yohimbine-induced reinstatement in the $\mathrm{eN}$ pHR3.0 virus condition $(40.5 \pm 6.7$ vs $78.3 \pm$ 18.7 active lever presses per $60 \mathrm{~min}$ for the light stimulation and no light, respectively, $\left.t_{(14)}=2.4, p=0.029\right)$ but not the eYFP virus condition $(43.4 \pm 8.0$ vs $55.5 \pm 9.1$ lever presses per $60 \mathrm{~min}$ for the light stimulation and no light, respectively, $p>0.05$ ). [Note that we assessed different durations of light stimulations for pellet priming and yohimbine, because the effect of the former on reinstatement is rarely observed beyond 30 min, whereas yohimbine effects on reinstatement can last for at least $3 \mathrm{~h}$ because of the long half-life of the drug (Nair et al., 2009)].

Experiment 7: phenotypic characterization of dorsal mPFC neurons activated by yohimbineinduced reinstatement. We examined the phenotype of dorsal mPFC neurons that were activated by yohimbine-induced reinstatement using a separate group of rats $(n=8)$. The rats underwent 10 training sessions, followed by 14 extinction sessions, and a single test for yohimbine-induced reinstatement, as described in experiments 5 and 6 . Two hours after the yohimbine injection, the rats were anesthetized and perfused, their brains were removed, and tissue was subsequently processed for Fos/CaMKII and Fos/GAD immunohistochemistry as described above.

\section{Statistical analyses}

The behavioral and molecular data were analyzed by ANOVAs and $t$ tests, and significant main effects and interaction effects $(p<0.05)$ were followed by Fisher's protected least significant difference or Bonferroni's post hoc tests. The dependent measures and the factors used in the statistical analyses are described in Results. Because some of our multifactorial ANOVAs yielded multiple main and interaction effects, we only report significant interaction or main effects that are critical for data interpretation.

\section{Results}

\section{Light delivery did not activate astrocytes or microglia} in $\mathrm{mPFC}$

We assessed whether laser light causes tissue damage in dorsal mPFC (inflammation or injury), as assessed by astrocyte (GFAP) and microglial activation (Iba-1) (Fig. 1) (Kreutzberg, 1996; Ridet et al., 1997). The raw data were analyzed using the betweensubjects factor of light (30 min of continuous light, intermittent light delivery $5 \mathrm{~s}$ cycles, or intermittent light delivery 5 min cycles) and the within-subject factor of hemisphere (light-exposed hemisphere, no-light hemisphere). The statistical analyses for either Iba-1 or GFP showed no main effects of intracranial light delivery or hemisphere or interaction between the two factors ( $p$ values $>0.05$ ). These results indicate that data interpretation 
Table 2. Electrophysiological properties of $\mathrm{MPFC}$ neurons in experiment 2

\begin{tabular}{lcc}
\hline & eNpHR3.0 - eYFP & eYFP \\
\hline Resting membrane potential $(\mathrm{mV})$ & $-72.9 \pm 2.1(n=9)$ & $-75.8 \pm 3.4(n=4)$ \\
Input resistance $(\mathrm{M} \Omega)$ & $142.7 \pm 18.5(n=9)$ & $121.5 \pm 30.9(n=4)$ \\
\hline
\end{tabular}

A

Effect of light on ex vivo neural activity

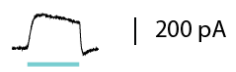

B

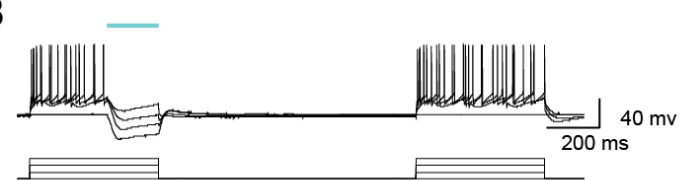

C

Linear relationship between light-evoked current and hyperpolarization

Current vs. membrane potential

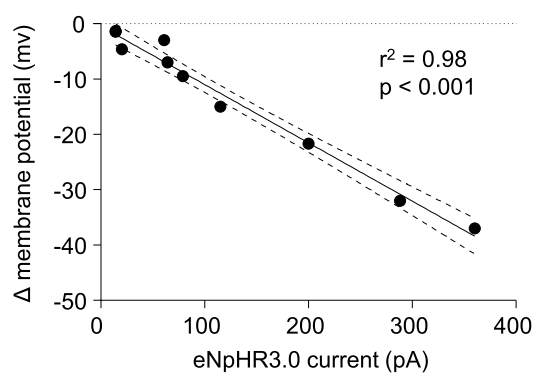

Figure 2. eNpHR3.0 activation decreased mPFC neuronal firing ex vivo. $A, A 200$ ms pulse of 532-nm light elicits robust outward current. $\boldsymbol{B}$, Left, Action potentials elicited by increasing current steps ( 500 ms, +200 pA steps) are suppressed by eNpHR3.0 activation (200 ms light pulse). Right, Injected currents reliably evoke spikes in the absence of eNpHR3.0 activation. Green bar denotes time of light activation. C, A linear relationship is observed between eNpHR3.0-mediated currents and membrane hyperpolarization. Data are from 10 neurons from four rats.

from experiments $2-6$ is not confounded by transient or irreversible light-induced neuronal injury processes.

\section{Light delivery in vitro decreased neural activity in dorsal mPFC}

We examined whether 532 or $593.5 \mathrm{~nm}$ light delivery attenuated neuronal activity in pyramidal neurons of dorsal mPFC brain sections expressing the eYFP and eNpHR3.0 constructs. Basic electrical properties of eNpHR3.0-expressing mPFC neurons were compared with those expressing only eYFP. There were no significant differences in the resting membrane potential or input resistance between these two groups (Table 2). Ex vivo whole-cell recordings from eNpHR3.0-expressing $\mathrm{mPFC}$ neurons showed light-evoked outward currents in 13 of 16 recorded neurons (169.6 $\pm 45.2 \mathrm{pA} ; n=13$ cells) (Fig. $2 A$ ). Neurons from mPFC transduced with the control virus, and CaMKII $\alpha$-eYFP did not exhibit light-evoked currents $(n=4)$. To determine whether eNpHR3.0-mediated hyperpolarization was effective in modulating neuronal firing, a $200 \mathrm{~ms}$ light pulse was delivered during direct current injection. Spike firing elicited by direct current injection was inhibited by eNpHR3.0-mediated hyperpolarization (Fig. 2B). The effect of eNpHR3.0-mediated outward current on membrane potential exhibited a linear relationship between light-evoked current and change in membrane potential. Lower light-evoked current induced a smaller membrane hyperpolarization, whereas greater light-induced hyperpolariza- tion was observed in neurons with larger light-evoked outward current $\left(r^{2}=0.98 ; p<0.01\right.$; Fig. $\left.2 C\right)$.

\section{Light delivery disrupted in vivo single-unit and population neural activity in dorsal mPFC of the awake rat}

We assessed whether light delivery inhibited neuronal activity in dorsal $\mathrm{mPFC}$ of awake, freely moving rats injected previously with the eNpHR3.0 construct. We recorded 35 single units in the dorsal mPFC across eight sessions in three awake, freely moving rats that received unilateral dorsal mPFC eNpHR3.0 injections 3-4 weeks before the first recording session. Figure $3 A$ shows a scatter plot of all 35 neurons comparing activity during $5 \mathrm{~s}$ light-on versus no-light baseline period (baseline: mean of $5 \mathrm{~s}$ pre-light epoch and $5 \mathrm{~s}$ post-light epoch) for each neuron. Firing in 14 of 35 (40\%) neurons decreased (Fig. $3 A$, red dots) during the $5 \mathrm{~s}$ intracranial light delivery relative to the no-light baseline period $\left(t_{(39)}=-2.5\right.$ to $\left.19.4 ; p<0.05\right)$. Figure $3 B$ provides a single-unit example of neural activity in a light-inhibited neuron (averaged across 40 trials of $5 \mathrm{~s}$ intracranial light delivery; aligned on light onset). Activity across the entire population of lightinhibited neurons was suppressed during the $5 \mathrm{~s}$ light delivery versus both the pre-light and post-light baseline periods $\left(t_{(13)}=\right.$ 3.6 , light vs pre; $t_{(13)}=4.0$, light vs post; $\left.p<0.05\right)$. Unexpectedly, 13 of $35(37 \%)$ single units recorded in dorsal mPFC showed excitatory responses (Fig. $3 A$, blue dots) during the brief $5 \mathrm{~s}$ light delivery relative to the no-light baseline period $\left(t_{(39)}=2.6-22.8\right.$; $p<0.05$ ) across 40 trials. Figure $3 C$ provides a single-unit example of neural activity in a light-excited neuron (averaged across 40 trials of $5 \mathrm{~s}$ intracranial light delivery; aligned on light onset). Activity across the entire population of light-excited neurons was increased during the $5 \mathrm{~s}$ light delivery versus both the pre-light and post-light baseline periods $\left(t_{(12)}=2.9\right.$, light vs pre; $t_{(12)}=$ 2.7 , light vs post; $p<0.05)$. Thus, short-duration light stimulation appears to both inhibit and activate dorsal mPFC neuronal activity.

Notably, the excitatory effect of light stimulation disappeared at longer stimulation periods, similar to that used in the behavioral experiments to follow, whereas the inhibitory effect persisted. This is evident in the scatter plot in Figure $3 D$, which compares activity during 2 min light-on versus $2 \mathrm{~min}$ no-light baseline period. Eight of 14 light-inhibited neurons were tested with 2 min duration intracranial light delivery (Fig. 3D, red dots). Three of these neurons (38\%) showed a reduction in firing across five trials during the light delivery versus the 2 min pre-light baseline period $\left(t_{(4)}=2.7-4.3 ; p<\right.$ $0.05)$, and overall, this population reduced firing during the 2 min light delivery period $\left(t_{(7)}=-2.8 ; p<0.05\right)$. In contrast, only one of the six light-excited neurons tested with 2 min duration light delivery (Fig. 3D, blue dots) showed increased firing across five trials during the light delivery versus the 2 min pre-light baseline period $\left(t_{(4)}=4.2 ; p<0.05\right)$, and the average activity across the entire population of light-excited neurons did not change during $2 \mathrm{~min}$ light delivery relative to the pre-light baseline period $(p>0.05)$. The lack of sustained excitability over $2 \mathrm{~min}$ in the light-excited population is evident in Figure $3 D$, because a few of the neurons that were excited by the brief, $5 \mathrm{~s}$ stimulation demonstrate reduced firing to the light across 2 min stimulation (blue dots that fall in the shaded area).

We also examined the effectiveness of the 30 min duration intracranial light delivery parameter (used in experiments 5 and 6). We tested five of the neurons that had been inhibited by the $5 \mathrm{~s}$ light pulse. As demonstrated in Figure $3 F$, activity averaged across 

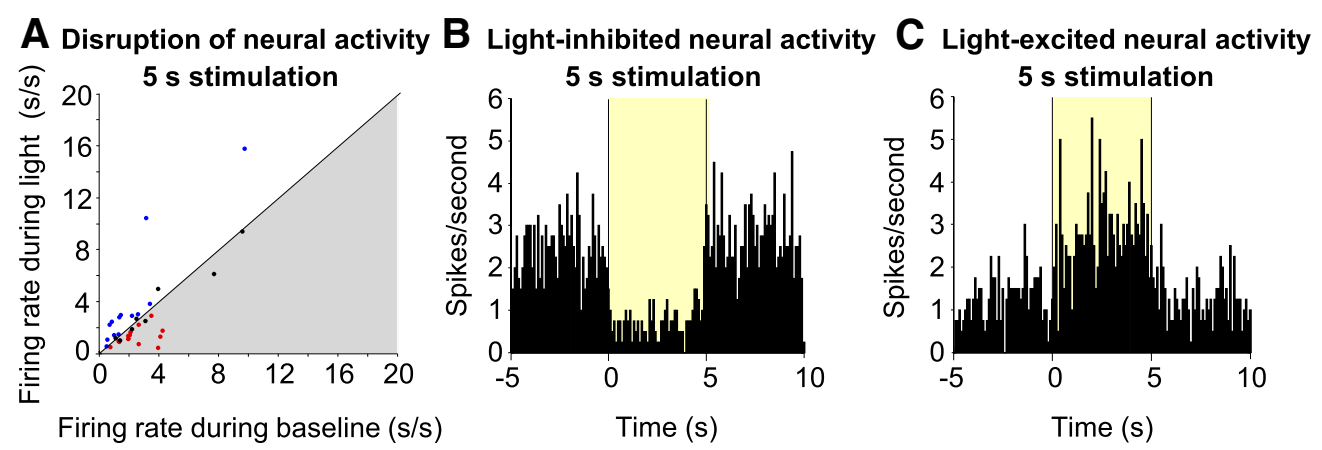

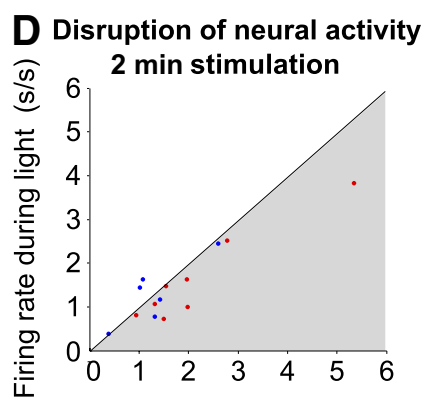

Firing rate during baseline (s/s)

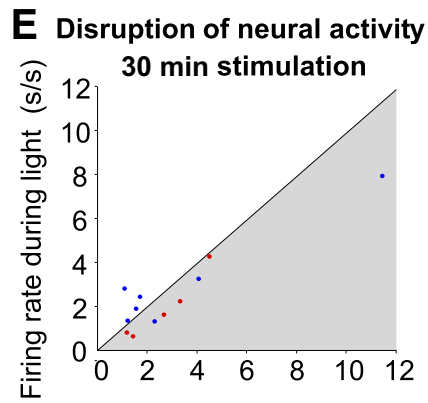

Firing rate during baseline (s/s)

\section{F Inhibition of population activity 30 min stimulation}

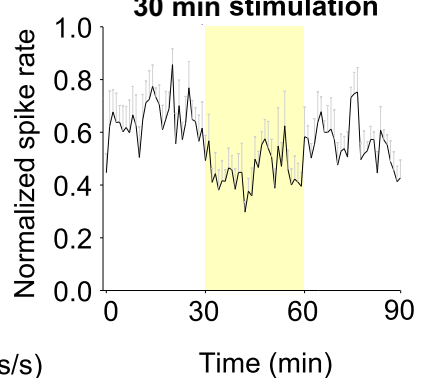

G Example of yohimbine-induced neuronal activation eYFP

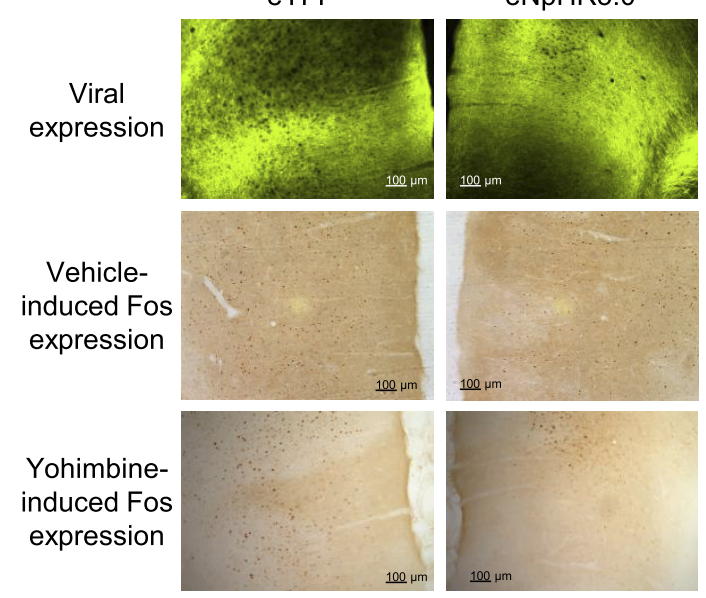

H Inhibition of yohimbine-induced neuronal activation

Fos expression

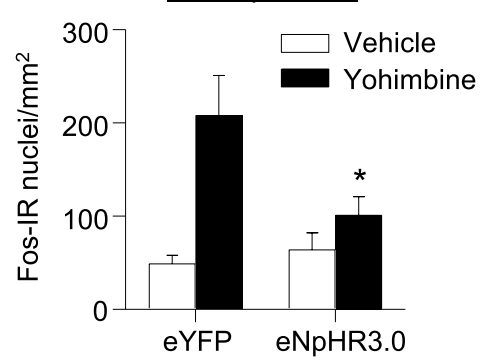

Figure 3. Light delivery in vivo decreased dorsal mPFC neuronal activity in awake rats and also decreased yohimbine-induced neuronal activation. $A$, Scatter plot of all 35 neurons comparing activity during $5 \mathrm{~s} \mathrm{light-on} \mathrm{versus} \mathrm{no-light} \mathrm{baseline} \mathrm{period} \mathrm{(baseline:} \mathrm{mean} \mathrm{of} 5 \mathrm{~s}$ pre-light epoch and $5 \mathrm{~s}$ post-light epoch) for each neuron. Red dots represent neurons that were defined as light inhibited (fire significantly less during 5 s light-delivery epoch vs baseline). Blue dots represent neurons that were defined as light excited (fire significantly more during $5 \mathrm{~s} \mathrm{light-delivery} \mathrm{epoch} \mathrm{vs}$ baseline). $\boldsymbol{B}$, In vivo single-unit example of neural activity in a light-inhibited neuron in dorsal mPFC from eNpHR3.0-expressing rat. Perievent histogram showing average neural activity for a light-inhibited single unit across 40 trials of $5 \mathrm{~s} 593.5 \mathrm{~nm}, 4-8 \mathrm{~mW}$ intracranial light delivery. Activity (100 ms time bins) is aligned on light delivery, and the yellow box denotes duration of optical stimulation. C, In vivo single-unit example of neural activity in a light-excited neuron in dorsal mPFC from eNpHR3.0-expressing rat. Perievent histogram showing average neural activity for a light-inhibited single unit across 40 trials of $5 \mathrm{~s} 593.5 \mathrm{~nm}, 4-8 \mathrm{~mW}$ intracranial light delivery. Activity ( $100 \mathrm{~ms}$ time bins) is aligned on light delivery, and the yellow box denotes duration of optical stimulation. $\boldsymbol{D}$, Scatter plot comparing activity during $2 \mathrm{~min}$ light-on versus $2 \mathrm{~min}$ no-light baseline period. Red and blue dots are the light-inhibited and light-excited neurons, respectively, as defined by their change in activity to the $5 \mathrm{~s}$ light stimulation parameter. Neurons that fall in the gray shaded area fire less during light delivery. $\boldsymbol{E}$, Scatter plot comparing activity during 30 min light-on versus $30 \mathrm{~min}$ no-light baseline period. Red and blue dots are the light-inhibited and light-excited neurons, respectively, as defined by their change in activity to the $5 \mathrm{~s}$ light stimulation parameter. Neurons that fall in the gray shaded area fire less during light delivery. $F$, Mean \pm SEM neural activity for a subpopulation of light-inhibited neurons ( $n=5$ neurons) during 30 min 593.5 $\mathrm{nm}, 4-8 \mathrm{~mW}$ intracranial light delivery. Activity (1 min time bins) is normalized to the maximum spike rate for each cell and is aligned on light delivery (yellow box denotes duration of optical stimulation). G, Example demonstrating the effect of bilateral intracranial light delivery on yohimbine-induced Fos expression. Example of sections demonstrating water-induced (middle row) and yohimbine-induced (bottom row) Fos expression in eYFP (left column) and eNpHR3.0 (right column) transfected hemispheres. Scale bars, $100 \mu \boldsymbol{m}$. $\boldsymbol{H}$, Effect of light delivery on water-and yohimbine ( $2 \mathrm{mg} / \mathrm{kg})$-induced Fos expression in dorsal mPFC ( $n=8$ water; $n=9$ yohimbine rats). Mean \pm SEM counts of Fos-immunoreactive nuclei $/ \mathrm{mm}^{2}$ in eYFP- and eNpHR3.0-expressing hemispheres of dorsal mPFC exposed to $90 \mathrm{~min}$ of $4-8 \mathrm{~mW} 593.5$ laser light. Different from $\mathrm{eYFP}^{*} \mathrm{p}<0.05$.

these neurons (Fig. 3E, red dots) was attenuated during the 30 min light-delivery period relative to the no-light baseline period (pre-light spike rate, $2.59 \pm 0.61$ spikes/s; light-on spike rate, $1.94 \pm 0.65$ spikes/s; $\left.t_{(4)}=-3.8 ; p<0.05\right)$. Seven of the 14 light-excited neurons were also tested with $30 \mathrm{~min}$ light delivery (Fig. $3 E$, blue dots), and statistical analysis of activity averaged across this subpopulation of seven neurons demonstrated no difference in neural activity during light delivery versus no-light baseline (pre-light 
spike rate, $3.3 \pm 1.4$ spikes/s; light-on spike rate, $3.0 \pm 0.86$ spike $/ s ; p>0.05)$. The lack of sustained excitability over $30 \mathrm{~min}$ in the light-excited population is evident in Figure $3 E$, because a few neurons that were excited to short-duration stimulation demonstrated an overall reduction in firing to the light across $30 \mathrm{~min}$ stimulation (blue dots that fall in the shaded area).

Together, the single-unit data suggest that the overall effect of $593.5 \mathrm{~nm}$ dorsal $\mathrm{mPFC}$ intracranial light delivery is to suppress neural activity, an effect that is most evident during long-duration optical (minutes timescale) stimulation.

Light delivery decreased yohimbineinduced Fos induction in mPFC

We assessed whether yohimbine-induced $\mathrm{mPFC}$ Fos induction is reversed by $\mathrm{mPFC}$ light delivery (Fig. 3G,H). Our previous studies have demonstrated a substantial yohimbine-induced neuronal activation in dorsal mPFC (Nair et al., 2011; Cifani et al., 2012). We examined the effect of light delivery on yohimbine-induced neuronal activation in rats ( $n=8-9$ per group) that were injected with the eYFP virus in one hemisphere and eNpHR3.0 virus in the other hemisphere and 5-6 weeks later received acute systemic injections of either water (vehicle) or yohimbine $(2 \mathrm{mg} / \mathrm{kg}$ ) and bilateral light delivery into the mPFC. The number of Fos ${ }^{+}$nuclei $/ \mathrm{mm}^{2}$ observed in the mPFC hemisphere injected with eYFP was comparable with that seen in our previous study after yohimbine injections (Nair et al., 2011). The statistical analysis of the number of Fos-immunoreactive cells, which included the within-subjects factor of virus and the between-subjects factor of yohimbine dose $(0,2 \mathrm{mg} / \mathrm{kg})$, demonstrated a significant effect of yohimbine dose $\left(F_{(1,15)}=10.7 ; p<0.01\right)$ and a significant interaction between virus and yohimbine dose $\left(F_{(1,15)}=6.6 ; p<0.05\right)$. Thus, under our experimental conditions, 4-8 mW $593.5 \mathrm{~nm}$ constant light delivery decreased yohimbine-induced mPFC neuronal activity, setting the stage for assessing the effect of this manipulation on yohimbine-induced reinstatement of food seeking.

In a separate group of rats $(n=3)$, we assessed the cell specificity of the eNpHR3.0-eYFP construct by bilaterally injecting this construct and examining eYFP expression in neuronal $\left(\mathrm{NeuN}^{+}\right)$ and astrocytic $\left(\mathrm{GFAP}^{+}\right) \mathrm{mPFC}$ cells 2 weeks after injection. We found that $85 \pm 5 \%$ of $\mathrm{eYFP}^{+}$cells were $\mathrm{NeuN}^{+}$, whereas only $1 \pm 0.7 \%$ of eYFP cells were $\mathrm{GFAP}^{+}$. This indicates that the expression of the eNpHR3.0 construct was restricted to dorsal mPFC neurons.

\section{A Fiber optic placement}

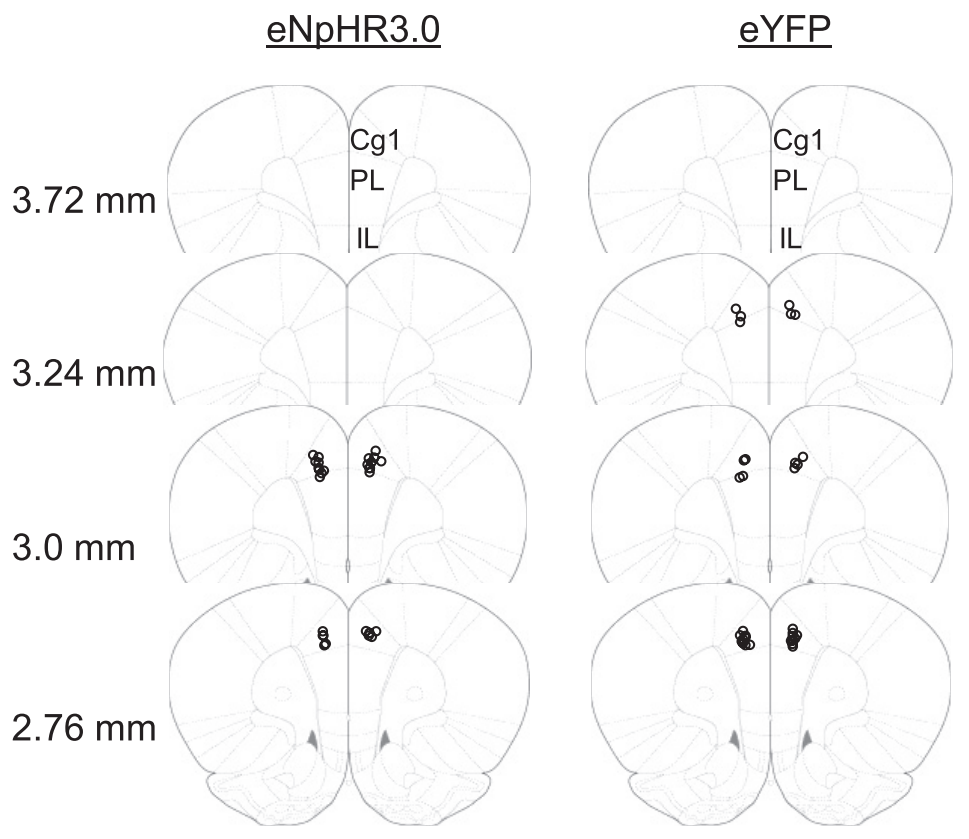

\section{B Viral expression at fiber site}

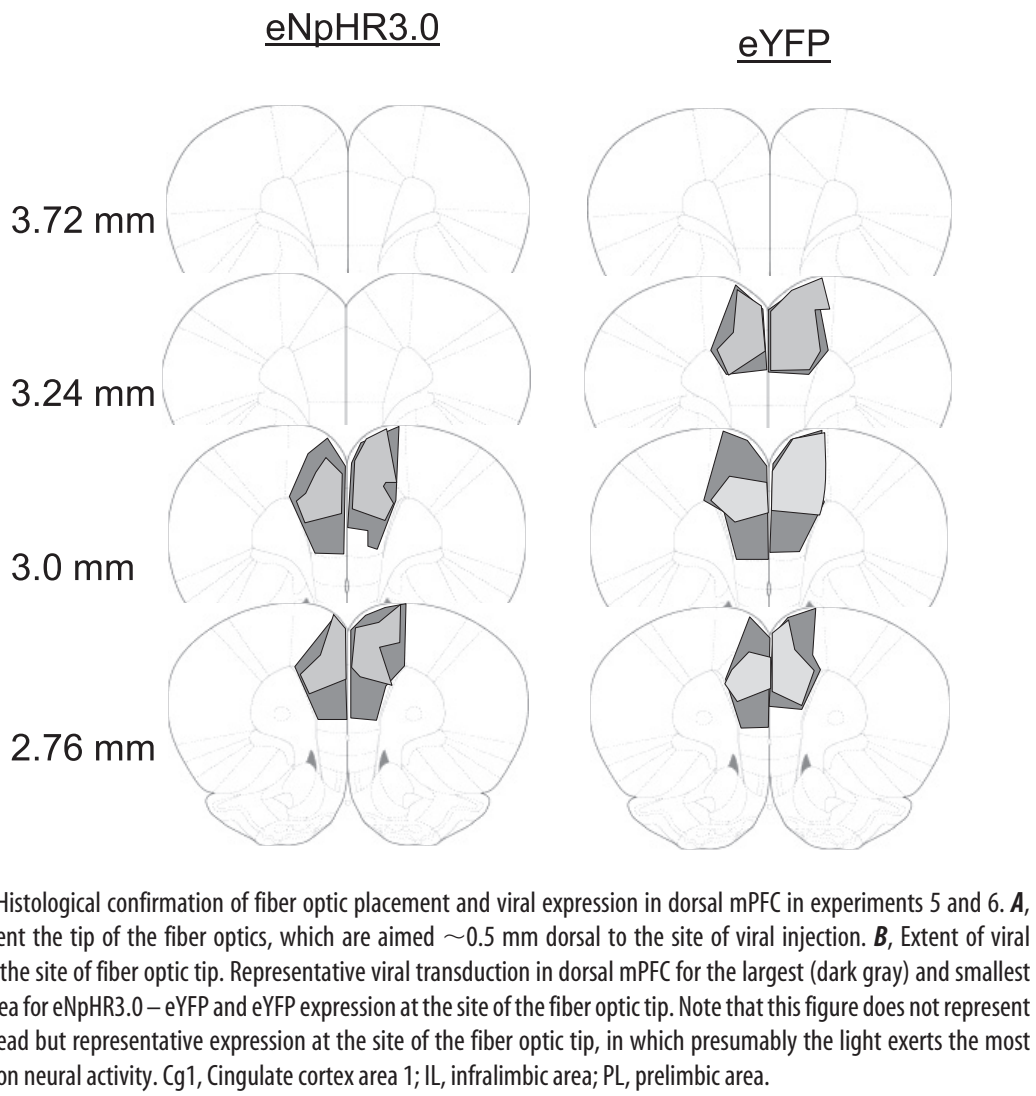

Figure 4. Histological confirmation of fiber optic placement and viral expression in dorsal $\mathrm{mPFC}$ in experiments 5 and $6 . \boldsymbol{A}_{\text {, }}$ Circles represent the tip of the fiber optics, which are aimed $\sim 0.5 \mathrm{~mm}$ dorsal to the site of viral injection. $\boldsymbol{B}$, Extent of viral expression at the site of fiber optic tip. Representative viral transduction in dorsal mPFC for the largest (dark gray) and smallest (light gray) area for eNpHR3.0 - eYFP and eYFP expression at the site of the fiber optic tip. Note that this figure does not represent total viral spread but representative expression at the site of the fiber optic tip, in which presumably the light exerts the most potent effect on neural activity. Cg1, Cingulate cortex area 1; IL, infralimbic area; PL, prelimbic area.

Dorsal mPFC light delivery decreased yohimbine-induced reinstatement of food seeking but had no effect on ongoing food self-administration or pellet-priming-induced reinstatement We assessed the impact of bilateral dorsal mPFC light delivery to rats injected bilaterally with either the eYFP virus or the 


\section{A Body weight}

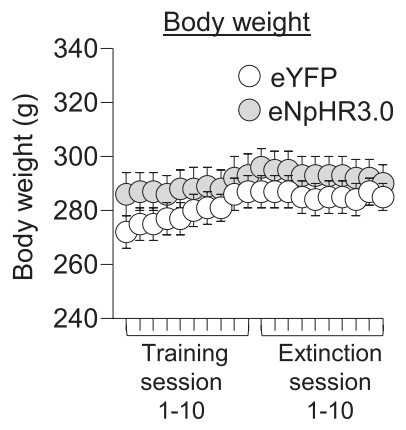

\section{Effect of light during training}

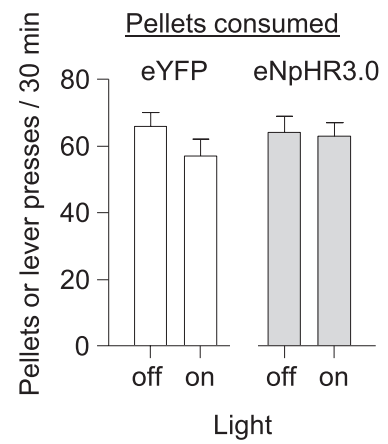

\section{B Training}

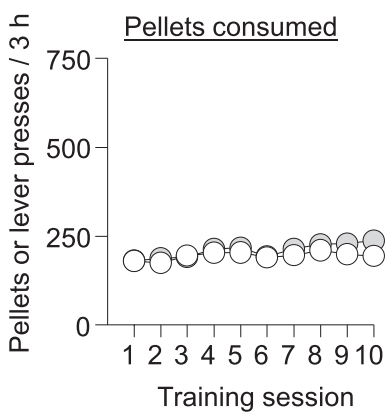

\section{Extinction}
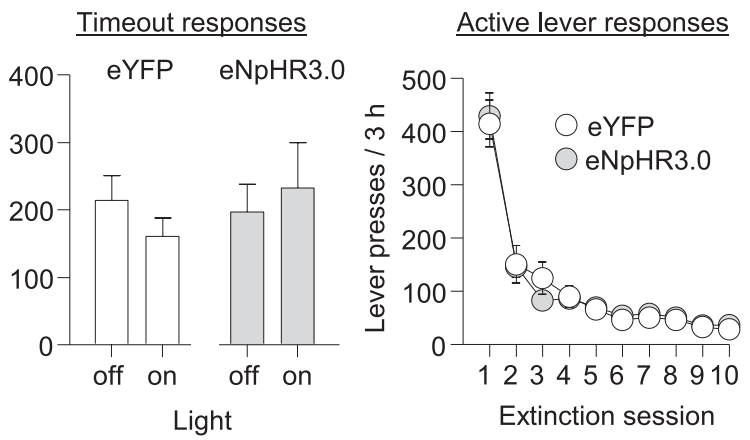

Figure 5. Viral expression has no effect on body weight, acquisition of ongoing food self-administration, or extinction of food-reinforced responding, and intracranial light delivery had no effect on ongoing food self-administration. $\boldsymbol{A}$, Body weight: mean \pm SEM body weights during the training and extinction phases. $\boldsymbol{B}$, Acquisition of food self-administration: mean \pm SEM number of food pellets earned and timeout responses on the active lever (total lever presses minus pellets earned) during the

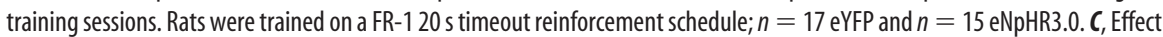
of dorsal mPFC light delivery during ongoing food self-administration: mean \pm SEM number of food pellets earned and timeout responses in the first 30 min of a training session when light was delivered and the subsequent training session for each rat when light was not delivered; $n=10$ per virus condition. $\boldsymbol{D}$, Extinction of food-reinforced responding: mean \pm SEM number of responses on the previously active lever; $n=14 \mathrm{eYFP}$ and $n=15 \mathrm{eNpHR3.0.}$

eNpHR3.0 virus on food self-administration, yohimbine- and pellet-priming-induced reinstatement of food seeking. Fiber optic placements are shown in Figure $4 A$, and the extent of viral expression for representative rats (largest, dark gray; and smallest, light gray) area of expression at the site of fiber optic implant) is shown in Figure $4 B$. eYFP and eNpHR3.0 rats exhibited no significant differences in body weight (Fig. $5 A$ ). During food selfadministration training, there were no group differences in the number of pellets consumed (Fig. $5 B$ ) or timeout responses (Fig. $5 B)$.

\section{Effect of light delivery on food}

self-administration

Intracranial light delivery had no effect on pellets consumed or timeout lever presses (Fig. 5C). The data were analyzed using the between-subjects factor of virus (eYFP, eNpHR3.0) and the within-subject factor of light (30 min continuous $593.5 \mathrm{~nm}$ intracranial light, $30 \mathrm{~min}$ no light). For both pellet intake and timeout lever responding, the ANOVAs showed no main effects of virus, light, or an interaction between the two factors ( $p$ values $>0.05$ ). These data indicate that neither light alone nor lightinduced activation of eNpHR3.0 in dorsal mPFC affects established operant responding for food.

\section{Extinction responding}

There were no group differences (eYFP vs eNpHR3.0) in extinction responding, which decreased over time in both groups (Fig.

$5 D)$. The statistical analysis, which included the between-subjects factor of virus (eYFP, eNpHR3.0) and the withinsubject factors of extinction session (sessions 1-10) and lever (active, inactive), showed a significant extinction session $X$ lever interaction $\left(F_{(9,243)}=79.8, p<\right.$ $0.01)$; there was no effect of virus or an interaction between virus and the other factors ( $p$ values $>0.05$ ).

\section{Effect of light delivery on reinstatement} Yohimbine $(2 \mathrm{mg} / \mathrm{kg})$ and pellet priming (four pellets) reinstated active lever pressing after extinction of food-reinforced responding, and this effect was independent of the virus injected (Fig. 6A). Dorsal $\mathrm{mPFC}$ light delivery in eNpHR3.0 rats but not eYFP control rats decreased yohimbine-induced reinstatement but not pellet-priming-induced reinstatement (Fig. 6A). The data were analyzed using the between-subjects factor of virus (eYFP, eNpHR3.0) and within-subject factors of reinstatement condition [water injections (control), four noncontingent pellets, $2 \mathrm{mg} / \mathrm{kg}$ yohimbine, counterbalanced], light delivery (30 min no intracranial light, $30 \mathrm{~min}$ continuous $593.5 \mathrm{~nm}$ intracranial light, counterbalanced), and lever (active, inactive). Inactive lever data are presented in Table 3. The ANOVA demonstrated significant interactions of reinstatement condition $\times$ lever $\left(F_{(2,54)}=\right.$ $19.40 ; p<0.01)$, virus $\times$ light $\left(F_{(1,27)}=\right.$ 5.32; $p<0.05)$, and virus $\times$ light $\times$ lever $\left(F_{(1,27)}=6.6 ; p<0.05\right)$. Post hoc analyses demonstrated that light delivery in $\mathrm{eN}$ pHR3.0 (but not eYFP) rats decreased yohimbine-induced reinstatement $(p<0.01)$.

\section{Yohimbine-induced reinstatement primarily activates pyramidal neurons in dorsal $\mathrm{mPFC}$}

Yohimbine $(2 \mathrm{mg} / \mathrm{kg}$ ) reinstated active lever pressing after extinction of food-reinforced responding (mean \pm SEM active lever presses during the last extinction session and the yohimbineinduced reinstatement test was $9 \pm 2$ and $86 \pm 26$ per $2 \mathrm{~h}$, respectively) (Fig. 6B). The data were analyzed using the within-subject factors of reinstatement condition (extinction, reinstatement) and lever. The ANOVA demonstrated a significant interaction for reinstatement condition $\times$ lever $\left(F_{(1,7)}=6.0 ; p<0.05\right)$. Results from the immunohistochemical double-labeling assay showed that $91 \pm 3 \%$ of $\mathrm{Fos}^{+}$neurons were $\mathrm{CaMKII}^{+}$and that $12 \pm 1 \%$ of Fos ${ }^{+}$neurons were $\mathrm{GAD}^{+}$(Fig. $6 \mathrm{~B}$ ). This finding suggests that yohimbine-induced reinstatement primarily activates pyramidal neurons in the dorsal mPFC.

\section{Discussion}

We used an optogenetic approach to study the role of the dorsal $\mathrm{mPFC}$ in reinstatement of food seeking in female rats induced by yohimbine, a pharmacological stressor that induces stress- and anxiety-like states in humans and nonhumans (Bremner et al., 1996a,b). We found that dorsal mPFC light delivery decreased 
yohimbine-induced reinstatement of food seeking in eNpHR3.0-injected but not eYFP-injected rats. This optogenetic manipulation had no effect on pellet-priminginduced reinstatement or ongoing foodreinforced responding, suggesting that the effect of the optogenetic manipulation on yohimbine-induced reinstatement is not attributable to nonspecific behaviorally disrupting effects of light stimulation. Dorsal mPFC light delivery also inhibited (1) yohimbine-induced Fos immunoreactivity, (2) neural activity during in vivo electrophysiological recording in awake rats, and (3) electrically evoked action potentials in vitro in eNpHR3.0-injected but not eYFPinjected $\mathrm{mPFC}$ hemispheres. Light delivery alone caused no significant inflammatory response in $\mathrm{mPFC}$ tissue. Together, we interpret these findings to suggest that light delivery in eNpHR3.0-injected rats disrupts endogenous dorsal mPFC neural activity that plays a role in stress-induced reinstatement of food seeking in female rats.

\section{Methodological considerations}

We selected 30-60 min constant light delivery because of the long half-life of yohimbine (Hubbard et al., 1988) and its effect on lever pressing during reinstatement testing, which persists for up to $3 \mathrm{~h}$ (Nair et al., 2009). Two concerns when using long-duration optical stimulation are tissue damage and eNpHR3.0 pump inactivation (or desensitization of lightevoked neuronal inhibition). We found no evidence for tissue damage, as assessed by astrocyte (GFAP) and microglia (Iba-1) activation, using a stimulation intensity (20 $\mathrm{mW}$ ) that was higher than the intensity used in our behavioral and electrophysiological experiments (4-8 $\mathrm{mW})$. Our in vivo electrophysiological data also provide little evidence for desensitization of light-evoked neuronal inhibition (Fig. 3); these data are in agreement with results from a study on the effect of prolonged hippocampal stimulation of eNpHR3.0-injected mice (Goshen et al., 2011). In our study, in vivo recording from eNpHR3.0-injected rats demonstrated persistent light sensitivity in response to 2 and $30 \mathrm{~min}$ stimulation across a population of lightinhibited neurons.

A concern from the $30 \mathrm{~min}$ light stimulation data is that neural activity is slow to recover to baseline levels after stimulation. Notably, our behavioral experiments compare data from the first 30 min of optical stimulation with data from a separate no intracranial light session at least $1 \mathrm{~d}$ later. Thus, any reduction in light sensitivity beyond $30 \mathrm{~min}$ is likely not relevant to our behavioral effect. Furthermore, our electrophysiological data acquired across days with a drivable optrode confirms that we continue to observe light-sensitive neuronal responses $24-48 \mathrm{~h}$ after longduration stimulation. Together, our data suggest that repeated within-subjects optical stimulation does not reduce the ability of the light to disrupt neural activity in eNpHR3.0-expressing rats.

Another aspect of this study to consider when interpreting the results relates to the cell specificity of the CaMKII $\alpha$ promoter
A Pellet-priming-and yohimbine-induced reinstatement

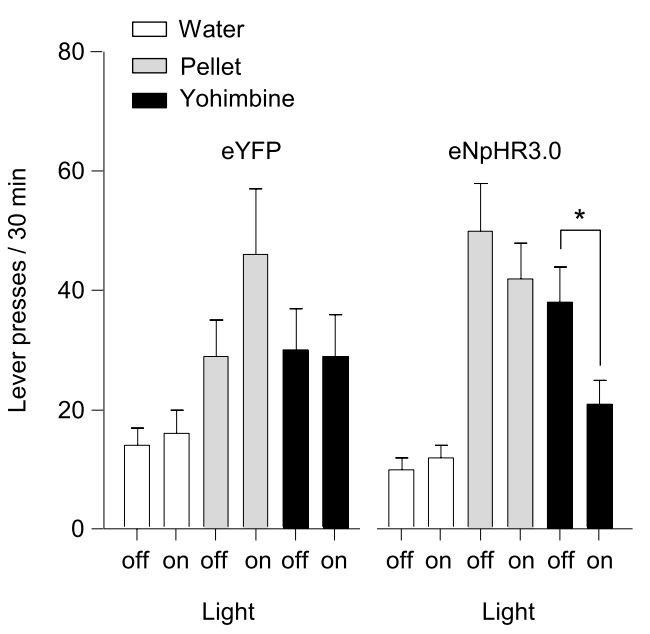

Phenotype of Yohimbine-induced Fos neurons in dmPFC

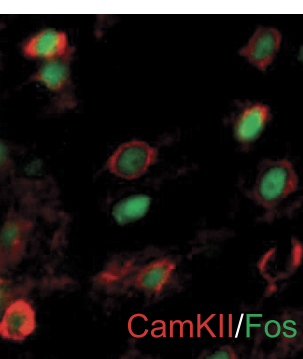

$\pm 13 \%$ of Fos-positive neurons were CamKII-positive

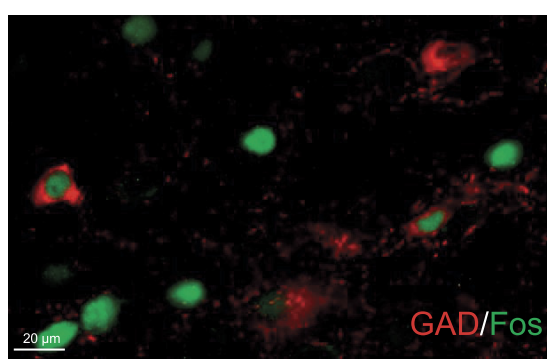

$12 \pm 1 \%$ of Fos-positive neurons were GAD-positive
Figure 6. Intracranial light delivery decreased yohimbine-induced reinstatement but not pellet-priming-induced reinstatement of food seeking in eNpHR3.0 but not eYFP rats. $\boldsymbol{A}$, Pellet priming-and yohimbine-induced reinstatement: mean \pm SEM active 列 (hession in which either four noncontingent pellets were delivered at the beginning of the session or yohimbine (intraperitoneal water injection) and the test off) condition, $p<0.01$. $B$, Phenotype of yohimbine-induced Fos neurons in dorsal mPFC: representative immunohistochemical staining of Fos ${ }^{+}$and CaMKII ${ }^{+}$(left) and Fos ${ }^{+}$and GAD ${ }^{+}$neurons (right). Scale bars, $20 \mu \mathrm{m}$.

Table 3. Inactive lever presses during the reinstatement tests in experiment 6

\begin{tabular}{lll}
\hline Group & Light off & Light on \\
\hline $\begin{array}{l}\text { Water } \\
\text { eYFP }\end{array}$ & \\
$\quad$ eNpHR3.0 & $1 \pm 1$ & $2 \pm 1$ \\
$\begin{array}{l}\text { Pellet } \\
\text { eYFP }\end{array}$ & $1 \pm 0.4$ & $1 \pm 0.5$ \\
eNpHR3.0 & & \\
Yohimbine & $2 \pm 1$ & $2 \pm 1$ \\
eYFP & $2 \pm 1$ & $2 \pm 1$ \\
eNpHR3.0 & & \\
\hline
\end{tabular}

system. Although CaMKII $\alpha$ immunohistochemistry is routinely used as a marker of glutamatergic pyramidal neurons (Liu and Jones, 1996), in a preliminary double-labeling assay, we observed some colabeling of eYFP with GAD67 $\left(7 \pm 4 \% \mathrm{eYFP}^{+}\right.$were $\mathrm{GAD}^{+} 7^{+}$), a marker of GABAergic interneurons (Kaufman et al., 1986). Thus, it is unlikely that, under our experimental conditions, light stimulation affected only glutamatergic neurons. Indeed, in our in vivo electrophysiology experiment, we observed some excitatory light-evoked responses in dorsal mPFC expressing eNpHR3.0 neurons. These excitatory responses may reflect 
disinhibition of pyramidal neurons by local GABAergic interneurons that express eNpHR3.0. Notably, although these excitatory responses were observed during brief optical stimulation, they were not sustained during the long-duration optical stimulation parameters that were used in our behavioral experiments. Furthermore, the finding that intracranial light delivery in eNpHR3.0-expressing mPFC neurons decreased yohimbineinduced neuronal activation (as assessed by Fos), together with the fact that long-duration optical stimulation in vivo caused sustained suppression of neural activity, suggest that the mPFC light delivery in eNpHR3.0-injected rats reduced local neural activity. Finally, we found that yohimbine-induced reinstatement primarily activates mPFC pyramidal $\left(\mathrm{CaMKII}^{+}\right)$neurons, suggesting that the effect of optical stimulation on this reinstatement is attributable to inhibition of glutamatergic projection neurons.

Another methodological issue that we did not assess is ovarian hormone fluctuations. However, it is unlikely that ovarian hormones play a role in the behavioral effects observed here, because we recently found that neither ovariectomy nor estrous cycle phase play a role in yohimibine-induced reinstatement of food seeking (Cifani et al., 2012). Another issue to consider is the interpretation of the negative findings on the lack of effect of mPFC light stimulation on food self-administration. This manipulation was performed $\sim 3$ weeks after viral injections, whereas the positive findings with yohimbine were obtained after 6-8 weeks of viral injections. Thus, it is possible that there was insufficient expression of the light-sensitive proteins to significantly disrupt neural activity at the 3 week time point.

\section{Role of dorsal mPFC in relapse to food seeking}

Our finding that optogenetic inhibition of dorsal mPFC decreased yohimbine-induced reinstatement in female rats is consistent with our previous finding in male rats (Nair et al., 2011). In that study, we found that systemic injections of the $\mathrm{D}_{1}$-family receptor antagonist SCH23390 $[R(+)-7$-chloro-8-hydroxy-3methyl-1-phenyl-2,3,4,5-tetrahydro- $1 \mathrm{H}$-3-benzazepine hydrochloride] blocked yohimbine-induced reinstatement and mPFC Fos induction and that SCH23390 injections into dorsal mPFC decreased this reinstatement. These data are in agreement with previous reports implicating the dorsal mPFC in stress-induced reinstatement of cocaine seeking (Capriles et al., 2003; Sanchez et al., 2003; McFarland et al., 2004). Notably, in our in vivo electrophysiology experiments, we observed a reduction but not total suppression of neural activity by light delivery. It is interesting that such a moderate inhibition, compared with more potent pharmacological inhibition of neural activity by GABA agonists, is similarly capable of attenuating stress-induced reinstatement.

Our finding that optogenetic inhibition of dorsal mPFC had no effect on pellet-priming-induced reinstatement in female rats is consistent with results from a previous study of McFarland and Kalivas (2001) who reported that reversible inactivation of the dorsal mPFC with muscimol plus baclofen (GABAergic agonists) had no effect on this reinstatement in male rats. However, our negative data for pellet priming are not consistent with our previous results (Nair et al., 2011) or with those of (Sun and Rebec, 2005), demonstrating that blockade of $D_{1}$ dopamine receptors in dorsal mPFC modestly decreased pellet-priming-induced reinstatement in male rats. In considering the different effects of reversible inactivation by either GABAergic agonists (McFarland and Kalivas, 2001) or optogenetic inhibition (present study) versus $\mathrm{D}_{1}$ dopamine receptor blockade (Sun and Rebec, 2005; Nair et al., 2011) on pellet-priming-induced reinstatement, it should be noted that others have also obtained different results in rein- statement studies, depending on whether reversible inactivation or $\mathrm{D}_{1}$ dopamine receptor blockade was used. For example, Floresco et al. (2008) reported that reversible inactivation of the accumbens shell with muscimol plus baclofen potentiates cueinduced food seeking. In contrast, Guy et al. (2011) reported that local $\mathrm{D}_{1}$ dopamine receptor blockade (injections were primarily in the shell and the border between core and shell) inhibits the same behavioral response. McFarland and Kalivas (2001) reported that cocaine-priming-induced reinstatement is blocked by injections of muscimol plus baclofen in accumbens core but not shell. In contrast, Anderson et al. (2003) reported that the same behavior is decreased by $\mathrm{D}_{1}$ dopamine receptor blockade with SCH23390 in accumbens shell but not core.

Finally, a question for future research is concerned with the terminal projections of mPFC glutamatergic neurons that contribute to yohimbine-induced reinstatement. To the degree that yohimbineinduced reinstatement of food seeking and footshock-stressinduced reinstatement of drug seeking are controlled by an overlapping circuitry, we speculate that the mPFC projections to accumbens core and ventral tegmental area (VTA) may play a critical role. Kalivas and colleagues have demonstrated a critical role of $\mathrm{mPFC}-$ accumbens core glutamatergic projection in footshockstress-induced reinstatement of cocaine seeking (McFarland et al., 2004; Kalivas, 2009). Wang et al. (2005) demonstrated a critical role of VTA glutamatergic transmission in this reinstatement; however, the source of the glutamatergic projection that mediates this VTAdependent stress-induced reinstatement is unknown.

\section{Concluding remarks}

We identified a causal role for the dorsal mPFC in stress-induced reinstatement of food seeking in female rats. There is a critical need to examine mechanisms of relapse to food seeking in female rats, because the proportion of women who use dietary supplements and seek dietary treatment is more than twice that of men (Davy et al., 2006; Pillitteri et al., 2008). Our study, together with recent studies examining the role of mPFC neurons in reinstatement of cocaine seeking (Stefanik et al., 2012) and VTA neurons in reinstatement of food seeking (Adamantidis et al., 2011) demonstrate the utility of combining the traditional reinstatement model (Epstein et al., 2006) with optogenetic approaches (Yizhar et al., 2011) to study the brain circuits of relapse to drug and food seeking.

\section{References}

Adamantidis AR, Tsai HC, Boutrel B, Zhang F, Stuber GD, Budygin EA, Touriño C, Bonci A, Deisseroth K, de Lecea L (2011) Optogenetic interrogation of dopaminergic modulation of the multiple phases of rewardseeking behavior. J Neurosci 31:10829-10835. CrossRef Medline

Anderson SM, Bari AA, Pierce RC (2003) Administration of the D1-like dopamine receptor antagonist SCH-23390 into the medial nucleus accumbens shell attenuates cocaine priming-induced reinstatement of drug-seeking behavior in rats. Psychopharmacology 168:132-138. CrossRef Medline

Bossert JM, Stern AL, Theberge FR, Cifani C, Koya E, Hope BT, Shaham Y (2011) Ventral medial prefrontal cortex neuronal ensembles mediate context-induced relapse to heroin. Nat Neurosci 14:420-422. CrossRef Medline

Bossert JM, Stern AL, Theberge FR, Marchant NJ, Wang HL, Morales M, Shaham Y (2012) Role of projections from ventral medial prefrontal cortex to nucleus accumbens shell in context-induced reinstatement of heroin seeking. J Neurosci 32:4982-4991. CrossRef Medline

Boyden ES, Zhang F, Bamberg E, Nagel G, Deisseroth K (2005) Millisecondtimescale, genetically targeted optical control of neural activity. Nat Neurosci 8:1263-1268. CrossRef Medline

Bremner JD, Krystal JH, Southwick SM, CharneyDS (1996a) Noradrenergic mechanisms in stress and anxiety. I. Preclinical studies. Synapse 23:28-38. CrossRef Medline 
Bremner JD, Krystal JH, Southwick SM, Charney DS (1996b) Noradrenergic mechanisms in stress and anxiety. II. Clinical studies. Synapse 23:39-51. CrossRef Medline

Capriles N, Rodaros D, Sorge RE, Stewart J (2003) A role for the prefrontal cortex in stress- and cocaine-induced reinstatement of cocaine seeking in rats. Psychopharmacology 168:66-74. CrossRef Medline

Cifani C, Koya E, Navarre BM, Calu DJ, Baumann MH, Marchant NJ, Liu QR, Khuc T, Pickel J, Lupica CR, Shaham Y, Hope BT (2012) Medial prefrontal cortex neuronal activation and synaptic alterations after stressinduced reinstatement of palatable food seeking: a study using c-fos-GFP transgenic female rats. J Neurosci 32:8480-8490. CrossRef Medline

Davy SR, Benes BA, Driskell JA (2006) Sex differences in dieting trends, eating habits, and nutrition beliefs of a group of midwestern college students. J Am Diet Assoc 106:1673-1677. CrossRef Medline

Epstein DH, Preston KL, Stewart J, Shaham Y (2006) Toward a model of drug relapse: an assessment of the validity of the reinstatement procedure. Psychopharmacology 189:1-16. CrossRef Medline

Floresco SB, McLaughlin RJ, Haluk DM (2008) Opposing roles for the nucleus accumbens core and shell in cue-induced reinstatement of foodseeking behavior. Neuroscience 154:877-884. CrossRef Medline

Ghitza UE, Gray SM, Epstein DH, Rice KC, Shaham Y (2006) The anxiogenic drug yohimbine reinstates palatable food seeking in a rat relapse model: a role of CRF(1) receptors. Neuropsychopharmacology 31:2188-2196. CrossRef Medline

Goshen I, Brodsky M, Prakash R, Wallace J, Gradinaru V, Ramakrishnan C, Deisseroth K (2011) Dynamics of retrieval strategies for remote memories. Cell 147:678-689. CrossRef Medline

Gradinaru V, Thompson KR, Deisseroth K (2008) eNpHR: a Natronomonas halorhodopsin enhanced for optogenetic applications. Brain Cell Biol 36:129-139. CrossRef Medline

Grilo CM, Shiffman S, Wing RR (1989) Relapse crises and coping among dieters. J Consult Clin Psychol 57:488-495. CrossRef Medline

Guy EG, Choi E, Pratt WE (2011) Nucleus accumbens dopamine and muopioid receptors modulate the reinstatement of food-seeking behavior by food-associated cues. Behav Brain Res 219:265-272. CrossRef Medline

Han X, Boyden ES (2007) Multiple-color optical activation, silencing, and desynchronization of neural activity, with single-spike temporal resolution. PLoS One 2:e299. CrossRef Medline

Howard DB, Powers K, Wang Y, Harvey BK (2008) Tropism and toxicity of adeno-associated viral vector serotypes $1,2,5,6,7,8$, and 9 in rat neurons and glia in vitro. Virology 372:24-34. CrossRef Medline

Hubbard JW, Pfister SL, Biediger AM, Herzig TC, Keeton TK (1988) The pharmacokinetic properties of yohimbine in the conscious rat. Naunyn Schmiedebergs Arch Pharmacol 337:583-587. CrossRef Medline

Kalivas PW (2009) The glutamate homeostasis hypothesis of addiction. Nat Rev Neurosci 10:561-572. CrossRef Medline

Kaufman DL, McGinnis JF, Krieger NR, Tobin AJ (1986) Brain glutamate decarboxylase cloned in lambda gt-11: fusion protein produces gammaaminobutyric acid. Science 232:1138-1140. CrossRef Medline

Kaufman DL, Houser CR, Tobin AJ (1991) Two forms of the gammaaminobutyric acid synthetic enzyme glutamate decarboxylase have distinct intraneuronal distributions and cofactor interactions. J Neurochem 56:720-723. CrossRef Medline

Koya E, Uejima JL, Wihbey KA, Bossert JM, Hope BT, Shaham Y (2009) Role of ventral medial prefrontal cortex in incubation of cocaine craving. Neuropharmacology 56 [Suppl 1]:177-185. CrossRef

Kramer FM, Jeffery RW, Forster JL, Snell MK (1989) Long-term follow-up of behavioral treatment for obesity: patterns of weight regain among men and women. Int J Obes 13:123-136. Medline

Kreutzberg GW (1996) Microglia: a sensor for pathological events in the CNS. Trends Neurosci 19:312-318. CrossRef Medline

Liu XB, Jones EG (1996) Localization of alpha type II calcium calmodulindependent protein kinase at glutamatergic but not gamma-aminobutyric acid (GABAergic) synapses in thalamus and cerebral cortex. Proc Natl Acad Sci U S A 93:7332-7336. CrossRef Medline

McFarland K, Kalivas PW (2001) The circuitry mediating cocaine-induced reinstatement of drug-seeking behavior. J Neurosci 21:8655-8663. Medline

McFarland K, Davidge SB, Lapish CC, Kalivas PW (2004) Limbic and motor circuitry underlying footshock-induced reinstatement of cocaine-seeking behavior. J Neurosci 24:1551-1560. CrossRef Medline

Morgan JI, Curran T (1991) Stimulus-transcription coupling in the nervous system: involvement of the inducible proto-oncogenes fos and jun. Annu Rev Neurosci 14:421-451. CrossRef Medline

Mullen RJ, Buck CR, Smith AM (1992) NeuN, a neuronal specific nuclear protein in vertebrates. Development 116:201-211. Medline

Nair SG, Adams-Deutsch T, Epstein DH, Shaham Y (2009) The neuropharmacology of relapse to food seeking: methodology, main findings, and comparison with relapse to drug seeking. Prog Neurobiol 89:18-45. CrossRef Medline

Nair SG, Navarre BM, Cifani C, Pickens CL, Bossert JM, Shaham Y (2011) Role of dorsal medial prefrontal cortex dopamine D1-family receptors in relapse to high-fat food seeking induced by the anxiogenic drug yohimbine. Neuropsychopharmacology 36:497-510. CrossRef Medline

Paxinos G, Watson C (2005) The rat brain in stereotaxic coordinates, Ed 5. Amsterdam: Elsevier Academic.

Peterson CB, Mitchell JE (1999) Psychosocial and pharmacological treatment of eating disorders: a review of research findings. J Clin Psychol 55:685-697. CrossRef Medline

Pickens CL, Cifani C, Navarre BM, Eichenbaum H, Theberge FR, Baumann MH, Calu DJ, Shaham Y (2012) Effect of fenfluramine on reinstatement of food seeking in female and male rats: implications for the predictive validity of the reinstatement model. Psychopharmacology 221:341-353. CrossRef Medline

Pillitteri JL, Shiffman S, Rohay JM, Harkins AM, Burton SL, Wadden TA (2008) Use of dietary supplements for weight loss in the United States: results of a national survey. Obesity (Silver Spring) 16:790-796. CrossRef Medline

Polivy J, Herman CP (1999) Distress and eating: why do dieters overeat? Int J Eat Disord 26:153-164. CrossRef Medline

Rabinowitz JE, Rolling F, Li C, Conrath H, Xiao W, Xiao X, Samulski RJ (2002) Cross-packaging of a single adeno-associated virus (AAV) type 2 vector genome into multiple AAV serotypes enables transduction with broad specificity. J Virol 76:791-801. CrossRef Medline

Ridet JL, Malhotra SK, Privat A, Gage FH (1997) Reactive astrocytes: cellular and molecular cues to biological function. Trends Neurosci 20:570577. CrossRef Medline

Sanchez CJ, Bailie TM, Wu WR, Li N, Sorg BA (2003) Manipulation of dopamine d1-like receptor activation in the rat medial prefrontal cortex alters stress- and cocaine-induced reinstatement of conditioned place preference behavior. Neuroscience 119:497-505. CrossRef Medline

See RE, Waters RP (2010) Pharmacologically-induced stress: a cross-species probe for translational research in drug addiction and relapse. Am J Transl Res 3:81-89. Medline

Shaham Y, Shalev U, Lu L, De Wit H, Stewart J (2003) The reinstatement model of drug relapse: history, methodology and major findings. Psychopharmacology 168:3-20. CrossRef Medline

Shepard JD, Bossert JM, Liu SY, Shaham Y (2004) The anxiogenic drug yohimbine reinstates methamphetamine seeking in a rat model of drug relapse. Biol Psychiatry 55:1082-1089. CrossRef Medline

Stefanik MT, Deisseroth K, Kalivas PW (2012) Optogenetic inhibition of cocaine seeking in rats. Addict Biol. Advance online publication. Retrieved November 16, 2012. doi:10.1111/j.1369-1600.2012.00479.x. CrossRef

Sun W, Rebec GV (2005) The role of prefrontal cortex D1-like and D2-like receptors in cocaine-seeking behavior in rats. Psychopharmacology 177: 315-323. CrossRef Medline

Tye KM, Deisseroth K (2012) Optogenetic investigation of neural circuits underlying brain disease in animal models. Nat Rev Neurosci 13:251-266. CrossRef Medline

Tye KM, Prakash R, Kim SY, Fenno LE, Grosenick L, Zarabi H, Thompson KR, Gradinaru V, Ramakrishnan C, Deisseroth K (2011) Amygdala circuitry mediating reversible and bidirectional control of anxiety. Nature 471:358-362. CrossRef Medline

Wang B, Shaham Y, Zitzman D, Azari S, Wise RA, You ZB (2005) Cocaine experience establishes control of midbrain glutamate and dopamine by CRF: a role in stress-induced relapse to drug-seeking. J Neurosci 25:5389 5396. CrossRef Medline

Xiao X, Li J, Samulski RJ (1998) Production of high-titer recombinant adeno-associated virus vectors in the absence of helper adenovirus. J Virol 72:2224-2232. Medline

Yizhar O, Fenno LE, Davidson TJ, Mogri M, Deisseroth K (2011) Optogenetics in neural systems. Neuron 71:9-34. CrossRef Medline

Zhang F, Aravanis AM, Adamantidis A, de Lecea L, Deisseroth K (2007a) 
Circuit-breakers: optical technologies for probing neural signals and systems. Nat Rev Neurosci 8:577-581. CrossRef Medline

Zhang F, Wang LP, Brauner M, Liewald JF, Kay K, Watzke N, Wood PG, Bamberg E, Nagel G, Gottschalk A, Deisseroth K (2007b) Multimodal fast optical interrogation of neural circuitry. Nature 446:633-639. CrossRef Medline
Zhao S, Cunha C, Zhang F, Liu Q, Gloss B, Deisseroth K, Augustine GJ, Feng G (2008) Improved expression of halorhodopsin for light-induced silencing of neuronal activity. Brain Cell Biol 36:141-154. CrossRef Medline 